\title{
A Study of AR-, TS-, and MCS-Associated Precipitation and Extreme Precipitation in Present and Warmer Climates
}

\author{
MING ZHAO ${ }^{\mathrm{a}}$ \\ ${ }^{a}$ Geophysical Fluid Dynamics Laboratory, Princeton, New Jersey
}

(Manuscript received 19 February 2021, in final form 18 October 2021)

\begin{abstract}
Atmospheric rivers (ARs), tropical storms (TSs), and mesoscale convective systems (MCSs) are important weather phenomena that often threaten society through heavy precipitation and strong winds. Despite their potentially vital role in global and regional hydrological cycles, their contributions to long-term mean and extreme precipitation have not been systematically explored at the global scale. Using observational and reanalysis data, and NOAA's Geophysical Fluid Dynamics Laboratory's new high-resolution global climate model, we quantify that despite their occasional (13\%) occurrence globally, AR, TS, and MCS days together account for $\sim 55 \%$ of global mean precipitation and $\sim 75 \%$ of extreme precipitation with daily rates exceeding its local 99th percentile. The model reproduces well the observed percentage of mean and extreme precipitation associated with AR, TS, and MCS days. In an idealized global warming simulation with a homogeneous SST increase of $4 \mathrm{~K}$, the modeled changes in global mean and regional distribution of precipitation correspond well with changes in AR/TS/MCS precipitation. Globally, the frequency of AR days increases and migrates toward higher latitudes while the frequency of TS days increases over the central Pacific and part of the south Indian Ocean with a decrease elsewhere. The frequency of MCS days tends to increase over parts of the equatorial western and eastern Pacific warm pools and high latitudes and decreases over most part of the tropics and subtropics. The AR/TS/MCS mean precipitation intensity increases by $\sim 5 \% \mathrm{~K}^{-1}$ due primarily to precipitation increases in the top $25 \%$ of AR/TS/MCS days with the heaviest precipitation, which are dominated by the thermodynamic component with the dynamic and microphysical components playing a secondary role.
\end{abstract}

KEYWORDS: Atmospheric river; Extreme events; Precipitation; Severe storms; Tropical cyclones; Mesoscale systems; General circulation models

\section{Introduction}

Atmospheric rivers (ARs), tropical storms (TSs), and mesoscale convective systems (MCSs) are spectacular weather phenomena that often pose a significant threat to society through heavy precipitation, strong winds, and associated disasters (e.g., Zhu and Newell 1994; Ralph et al. 2019; Emanuel 2018; Knutson et al. 2019, 2020; Houze 2004, 2018). Despite their potentially vital role in global and regional hydrological cycles, the contributions of ARs, TSs, and MCSs to long-term global and regional mean and extreme precipitation have not been systematically quantified at the global scale from both observations and models. Previous studies focus only on individual phenomena often over limited regions and/or seasons (e.g., Ralph et al. 2006; Lavers and Villarini 2013, 2015; Dettinger 2013; Nayak and Villarini 2017; Prat and Nelson 2013; Cheeks et al. 2020) with a few TS studies covering the entire tropical region (e.g., Jiang and Zipser 2010; Prat and Nelson 2016). From the observational point of view, this was due primarily to limited measurement, data availability, and a short observational record. However, a recent effort (Beck et al. 2019) combining many satellite observations and reanalysis data provided a Multi-Source Weighted-Ensemble Precipitation (MSWEP-v2) dataset that provides fine spatial and temporal resolution data with global coverage for multiple decades (1979-present). This new observational estimate of global high-frequency precipitation rate along with reanalysis data, the observed TS tracks, and

Corresponding author: Ming Zhao, Ming.Zhao@noaa.gov multisatellite measurement of infrared brightness temperature would make it possible to simultaneously quantify AR-, TS-, and MCS-associated precipitation and extreme precipitation at global scale.

From the numerical modeling point of view, the lack of these kinds of studies is due at least in part to the fact that typical global climate models (GCMs), which are designed to run for many decades to a century, do not have sufficient horizontal resolution to realistically simulate all of these phenomena. While future increases in modeling resolution will continue to improve GCM fidelity in simulating these phenomena, recent efforts at NOAA's Geophysical Fluid Dynamics Laboratory (GFDL) suggest that even at a moderately high horizontal resolution (e.g., $50 \mathrm{~km}$ ) some GCMs can reasonably well simulate many aspects of the observed ARs (Zhao 2020), TSs (Zhao et al. 2009, 2010; Murakami et al. 2020), and even MCSs (Dong et al. 2021), including their climatology and variability. However, the detection and tracking algorithms for ARs, TSs, and MCSs do not typically involve the precipitation field (e.g., Guan and Waliser 2015; Shields et al. 2018; Zhao et al. 2009; Horn et al. 2014; Hodges et al. 2000; Huang et al. 2018; Dong et al. 2021). In comparison to storm frequency, the analysis of stormassociated precipitation has received much less attention. Existing analyses of storm-associated precipitation focus mostly on individual phenomena often over limited regions of the globe (e.g., Slinskey et al. 2020; Gao and Leung 2016; Hagos et al. 2016; Knutson et al. 2010, 2020; Prat and Nelson 2013, 2016; Scoccimarro et al. 2014). To the best of the author's knowledge, the combined contributions of these storms to global and 
regional mean and extreme precipitation have never been studied and documented.

The goal of this study is to use observational and reanalysis data as well as the GFDL new high-resolution GCM, which has been demonstrated to realistically simulate ARs (Zhao 2020), TSs (Murakami et al. 2020), and MCSs (Dong et al. 2021), to explore the precipitation characteristics associated with ARs, TSs, and MCSs in the present climate as well as their response to global warming. In particular, we attempt to address the following questions. 1) How much of present-day climatological precipitation and extreme precipitation may be attributed to ARs, TSs, and MCSs? 2) How may the mean and extreme precipitation associated with ARs, TSs, and MCSs change in a warmer climate? 3) How may we understand the change in mean and extreme precipitation associated with ARs, TSs, and MCSs? Below section 2 describes the model, the simulations, the observational data, and the methods for detecting AR, TS, and MCS days. Section 3 presents the AR/TS/MCS-associated precipitation and extreme precipitation in the present climate. Section 4 explores the changes in AR/TS/MCS-associated precipitation in a warmer climate. Section 5 provides a summary.

\section{The model, simulations, storm detection methods, and observational data}

The model (referred to as C192AM4; Zhao 2020) we utilized here is a high-resolution version of the GFDL atmospheric model version 4 (AM4). AM4 (Zhao et al. 2018a,b) has been used in GFDL's new physical climate model CM4 (Held et al. 2019) and Earth System Model ESM4 (Dunne et al. 2020) for GFDL's participation in phase 6 of the Coupled Model Intercomparison Project (CMIP6; Eyring et al. 2016). In addition, AM4 has also been used in GFDL's Seamless system for Prediction and Earth system Research (SPEAR; Delworth et al. 2020). C192AM4 employs a cubed-sphere topology for its atmospheric dynamical core with $192 \times 192$ grid boxes per cube face corresponding to roughly $\sim 50-\mathrm{km}$ horizontal grid spacing. C192AM4 has been used for GFDL's participation in the CMIP6 High Resolution Model Intercomparison Project (Haarsma et al. 2016).

For this study, we analyzed three C192AM4 simulations. The first is a present-day simulation for the period of 1979-2014 (referred to as PRESENT), with the model forced by the observed daily SSTs, sea ice concentrations, and radiative gases following the CMIP6 HighResMIP specifications. This simulation corresponds to the HighResMIP Tier 1 highresSST-present simulation (Haarsma et al. 2016). This simulation is used to evaluate the model's ability in simulating ARs, TSs, MCSs, and their associated precipitation and extreme precipitation in comparisons with the observations. In addition, we have conducted two 100-yr simulations for studies of storm associated precipitation under an idealized global warming scenario. The first (referred to as CLIMO) is a $100-y r$ present-day climatological simulation, with the model forced by the observed monthly varying climatological SSTs and sea ice concentrations (averaged for the 1980-2014 period) and with the radiative gases and aerosol emissions fixed at the year 2010 condition. Thus, this simulation does not contain any interannual variabilities of forcings. The second simulation is an idealized global warming experiment that is identical to CLIMO except with SSTs uniformly increased by $4 \mathrm{~K}$ (referred to as $\mathrm{P} 4 \mathrm{~K}$ ). The warming simulation is used to explore the possible change in AR, TS, and MCS associated precipitation and extreme precipitation in a future warmer climate. All model outputs are first interpolated from the model's native cubed-sphere grid to a latitude-longitude (lat-lon) grid. For TS detection and tracking, we used the model output at $0.5^{\circ} \times 0.625^{\circ}$ (lat $\times$ lon) resolution, which is the typical resolution we use for C192AM4. For all other analysis, we regrid the model data to $0.75^{\circ} \times 0.75^{\circ}$ (lat $\times$ lon) resolution. This slightly lower resolution was previously chosen to facilitate the model's comparison of AR statistics with the ECMWF interim reanalysis (ERA-Interim) results at the same resolution (Zhao 2020). It also helps to reduce the overall volume of data, which becomes very large for the 100-yr simulations (i.e., CLIMO and $\mathrm{P} 4 \mathrm{~K}$ ) with 6-hourly outputs.

The AR detection method is identical to that used in Zhao (2020) and Guan and Waliser (2015). The algorithm uses 6hourly outputs of zonal and meridional vertically integrated vapor transport (IVT) to compute the IVT magnitude at each grid cell, and it does not track individual ARs over time so that each map of IVT magnitude is treated independently. The algorithm starts with thresholding each instantaneous IVT field based on the 85th percentile specific to each season (i.e., percentile calculated over all time steps during the 5 months centered on that month) and grid cell for each experiment with a fixed lower limit of $100 \mathrm{~kg} \mathrm{~m}^{-1} \mathrm{~s}^{-1}$. Zhao (2020) compared the global distribution of the 85th percentile of IVT magnitude derived from the PRESENT, CLIMO, and P4K simulations (see Fig. 9 in Zhao 2020). While the difference is very small between CLIMO and PRESENT, there is a huge increase from CLIMO to P4K due to the 4-K increase in SSTs. The use of IVT 85th percentile from each experiment for thresholding its IVT fields would automatically and consistently take into account the change in background state of moisture transport in $\mathrm{P} 4 \mathrm{~K}$. We refer to Zhao (2020) for a detailed discussion of the rationale of using the warmer climate's IVT 85th percentile for detecting ARs in the warmer climate simulation. A similar method has also been used in literature (e.g., Shields and Kiehl 2016). After thresholding each IVT field, the identified AR candidates are then checked for the geometry requirement of length $>2000$ $\mathrm{km}$, length-to-width ratio $>2$, and other considerations indicative of the AR conditions. These include a requirement of appreciable poleward transport of moisture $\left(>50 \mathrm{~kg} \mathrm{~m}^{-1} \mathrm{~s}^{-1}\right)$ and coherence of IVT direction (i.e., the fraction of AR grid cells with local IVT directed within $45^{\circ}$ of the AR's mean IVT direction must be greater than 0.5 ). The AR detection algorithm provides 6-hourly output of AR objects as well as some basic measurements of each detected AR such as length, width, mean zonal and meridional IVT, and the coherence of IVT direction (Guan and Waliser 2015). We use the AR objects to identify grid cells that experience AR conditions, which are further utilized to determine the AR days. 
The TS detection method follows that used in Zhao et al. $(2009,2012)$. To give a brief summary, we first identify potential cyclones by locating local maximums of $850-\mathrm{hPa}$ relative vorticity exceeding a threshold value $\left(3.5 \times 10^{-5} \mathrm{~s}^{-1}\right)$ and defining their nearby local minimums of sea level pressure as cyclone centers using 6-hourly instantaneous fields of $850-\mathrm{hPa}$ relative vorticity and sea level pressure. We then track individual tropical cyclones (TCs) using the 6-hourly cyclone locations. The latitude of the first point (genesis location) of a TC track must be within $30^{\circ} \mathrm{S}-30^{\circ} \mathrm{N}$. After a TC track is identified it is categorized as a TS if it satisfies all of the following three criteria for at least 3 days (not necessarily consecutive): 1) maximum surface wind speed $\geq 17 \mathrm{~m} \mathrm{~s}^{-1}$, 2) maximum 850$\mathrm{hPa}$ relative vorticity $\geq 1.6 \times 10^{-4} \mathrm{~s}^{-1}$, and 3) warm-core temperature anomaly $\geq 2 \mathrm{~K}$. We assume the $12^{\circ} \times 12^{\circ}$ (lat $\times$ lon) region centered at each TS's center location as the area experiencing a TS condition.

The MCS detection method follows that used in Dong et al. (2021) and Huang et al. (2018). We first derive the brightness temperature $T_{b}$ from the top of atmosphere (TOA) outgoing longwave radiation (OLR) based on the following equations (Dong et al. 2021; Ellingson and Ferraro 1983):

$$
\begin{gathered}
T_{F}=T_{b}\left(a+b T_{b}\right), \\
\text { OLR }=\sigma T_{F}^{4},
\end{gathered}
$$

where $T_{F}$ is the flux equivalent brightness temperature, $\sigma=$ $5.67 \times 10^{-8} \mathrm{~W} \mathrm{~m}^{-2} \mathrm{~K}^{-4}$ is the Stefan-Boltzmann constant, and $a$ and $b$ are empirical coefficients based on regression (Ohring et al. 1984). Following Ellingson and Ferraro (1983) and Dong et al. (2021), we set $a=1.228$ and $b=-1.106 \times$ $10^{-3} \mathrm{~K}^{-1}$. The algorithm first thresholds each 6-hourly instantaneous field of $T_{b}$ by removing any grid cells with $T_{b}$ values greater than $233 \mathrm{~K}$ (e.g., Huang et al. 2018; Dong et al. 2021). Because the data resolution is $0.75^{\circ} \times 0.75^{\circ}$ (lat $\times$ lon), which is already larger than the smallest size of MCSs, we do not further apply a size threshold for MCSs and simply consider any grid cells whose $T_{b}$ values are below this threshold as regions experiencing MCS conditions.

It is worth noting that Dong et al. (2021) studied MCSs only over the tropical regions. For MCSs over middle and high latitudes, the use of a single absolute value of $T_{b}$ threshold is not sufficient in detecting MCSs due to the much smaller values of climatological $T_{b}$ at high latitudes. Thus, we include an additional criterion by removing any grid cells whose $T_{b}$ values are not $30 \mathrm{~K}$ smaller than the zonal mean values of the climatological $T_{b}$ at the same latitude and same time of year-that is, $T_{b}(\lambda, \phi, t) \geq\left[\overline{T_{b}(\lambda, \phi, t)}\right]-30 \mathrm{~K}$, where the overbar and square bracket denote respectively an average across all years and all longitudes $\lambda$ at a given latitude $\phi$ and time of year $\tau$ so that $\left[\overline{T_{b}(\lambda, \phi, t)}\right]$ is a function of $\phi$ and $\tau$ only. The climatological $T_{b}$ [i.e., $\overline{T_{b}(\lambda, \phi, t)}$ ] is computed by taking a long-term (1979-2014 for PRESENT, 100 years for CLIMO and P4K) average of the 6-hourly $T_{b}$ field at each location $(\lambda, \phi)$ and time of year $\tau$. This additional criterion has little impact over the tropics because the tropical zonal mean values of climatological $T_{b}$ \{i.e., $\left.\left[\overline{T_{b}(\lambda, \phi, \tau)}\right]\right\}$ are always at least $30 \mathrm{~K}$ greater than $233 \mathrm{~K}$. In short, we consider any grid cells whose $T_{b}$ values satisfy the above two criteria-namely, $T_{b}(\lambda, \phi, t) \leq 233 \mathrm{~K}$ and $T_{b}(\lambda, \phi, t)<\left[\overline{T_{b}(\lambda, \phi, t)}\right]-30 \mathrm{~K}$ - as regions in MCS conditions.

Finally, for any given grid cells, if at least one AR/TS/MCS condition is identified from the 6-hourly data during a calendar day and the daily surface precipitation exceed $1 \mathrm{~mm}$ day $^{-1}$, the day is subsequently identified as an AR/TS/MCS day. We also make AR, TS, and MCS days mutually exclusive by setting a priority for each identified phenomenon. In particular, for any given grid cells, if a day satisfies multiple conditions, it is first considered as a TS day, then an AR day, and finally an MCS day. This priority choice is partly due to our confidence level for detecting TS, AR, and MCS days. The overlaps between ARs and TSs are generally small due to their large differences in main development regions (i.e., midlatitudes vs tropics) although they could be significant during summer and fall seasons at the latitude of TS extratropical transition. Among the three phenomena, we have a relatively lower confidence for detecting MCS; thus, we consider a day as an MCS day only when it is neither an AR nor a TS day. With this priority, for any given grid cells, a calendar day is classified as one of the following four categories: AR day, TS day, MCS day, or nothing. Using this classification, we conditionally sample daily precipitation fields as well as other meteorological variables to explore the contributions of AR, TS, and MCS days to global and regional mean and extreme precipitation as well as their changes with global warming.

The identical methods described above are also used to detect the observed AR, TS, and MCS days and their associated precipitation. The observed daily precipitation data (1979-2014) are from Beck et al. (2019) (referred to as MSWEP-v2). The observed 6-hourly AR objects are derived from the ERA-Interim reanalysis data using the same AR detection method described above (Zhao 2020). The global TS track data are obtained from the International Best Track Archive for Climate Stewardship (IBTrACS) (Knapp et al. 2010). To detect MCS days, we use the Cloud Archive User Service (CLAUS) multisatellite infrared brightness temperature dataset (Hodges et al. 2000), which provides 3-hourly global coverage of $T_{b}$ for the 1985-2008 period. Except that the climatological $T_{b}$ is computed using the shorter observational record, the MCS detection method is identical to that described above. All the observational data are first regridded to the same resolution (i.e., $0.75^{\circ} \times 0.75^{\circ}$ ) as ERA-Interim to facilitate comparisons with the model. Below we describe the results from the observations and the model's present-day simulation.

\section{AR/TS/MCS precipitation in present climate}

We first present in Fig. 1 the geographical distribution of the occurrence frequency of the observed and modeled AR, TS, and MCS days. The global and annual mean frequencies of the AR, TS, and MCS days are, respectively, $8.33 \%$, 

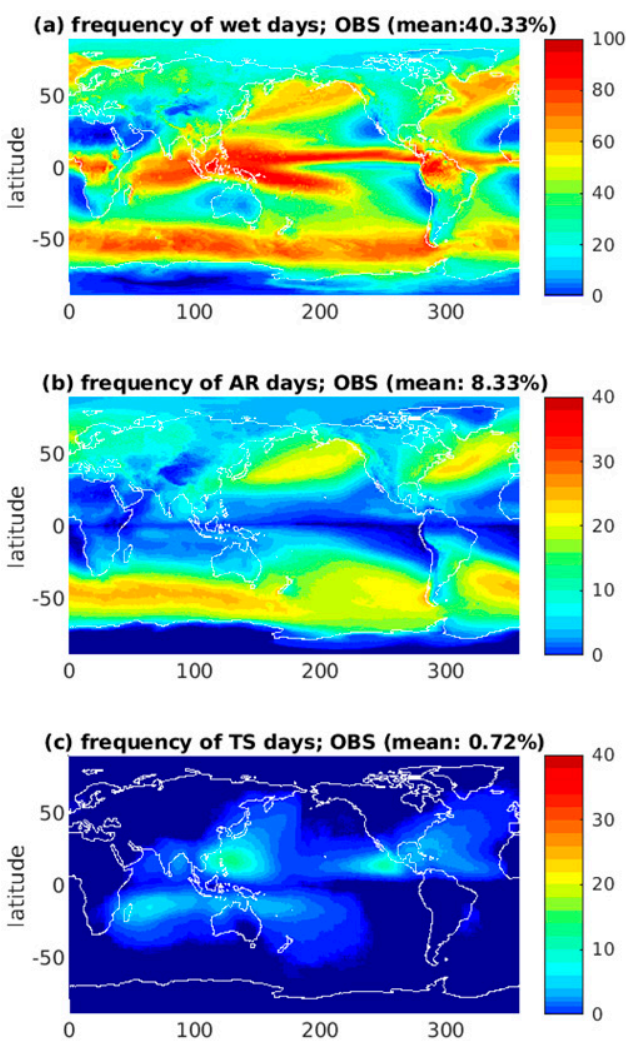

(d) frequency of MCS days; OBS (mean: 4.28\%)

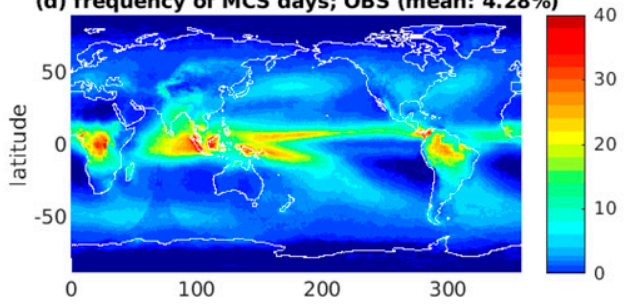

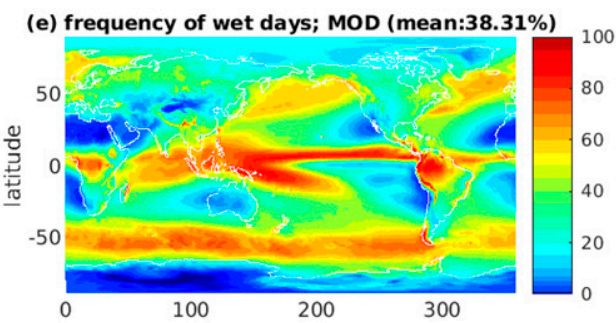
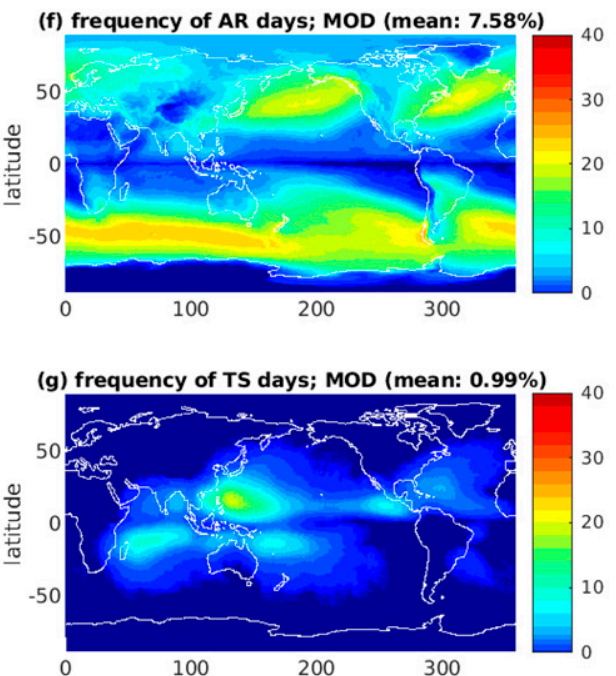

(h) frequency of MCS days; MOD (mean: 4.37\%)

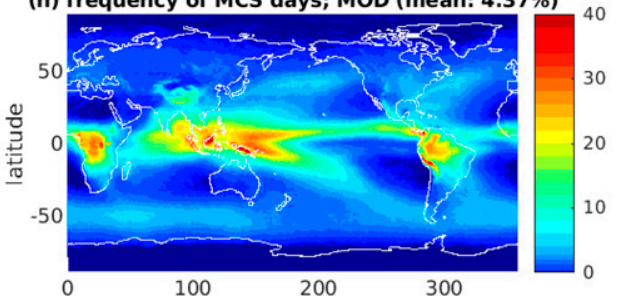

FIG. 1. (a) Geographical distribution of the occurrence frequency (\%) of the annual wet days (defined as daily precipitation rate $>1 \mathrm{~mm}^{-1} \mathrm{yy}^{-1}$ ) based on MSWEP-v2 precipitation dataset. (b)-(d) As in (a), but for the annual frequency of AR (based on ERA-Interim), TS (based on IBTrACS), and MCS (based on CLAUS) days, respectively. The global area-weighted mean value is shown on the top of each panel. (e)-(h) As in (a)-(d), but for the model results from PRESENT.

$0.72 \%$, and $4.28 \%$ from the observations and $7.58 \%, 0.99 \%$, and $4.37 \%$ from the model. Thus, they may be considered relatively rare events globally. Regionally, they may occur more frequently. For example, the maximum frequency of AR days over the midlatitude storm track regions is around $20 \%-25 \%$ while the TS and MCS days tend to occur more frequently in the tropical and subtropical regions with the MCS days appearing $\sim 30 \%$ of the time over parts of the equatorial western Pacific, Africa, and the South American Amazon basin. TS days occur most frequently over the tropical off-equatorial TC main development regions (MDR) where SSTs are warmer. Globally, the frequency of AR, TS, and MCS days together amount to $\sim 13 \%$, which is roughly one-third of the frequency of all wet days (defined here as daily precipitation $\geq 1 \mathrm{~mm} \mathrm{day}^{-1}$ ) in both the observations and the model (see Figs. 1a,e).

While the model broadly captures the observed geographical distribution of the frequency of AR/TS/MCS days, it also displays significant regional biases. For example, the model tends to overproduce the frequency of TS days over the western Pacific and underestimate them over the North Atlantic and the eastern Pacific, a typical bias seen in most high-resolution GCMs (e.g., Shaevitz et al. 2014). The model also slightly underestimates annual AR frequency over midlatitude storm track regions. For MCSs, the model overproduces annual frequencies over the western Pacific, especially to the east of the Philippines, while underestimating them over the equatorial south Indian Ocean. Over the Atlantic and North American 


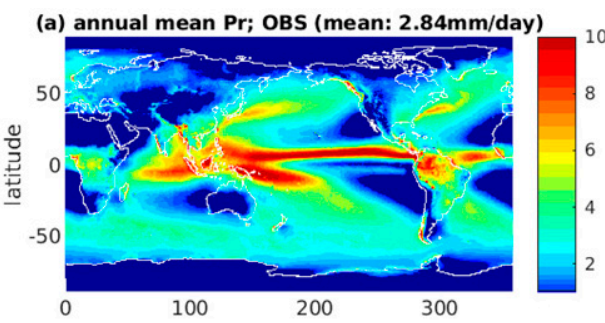

(b) annual mean Pr from AR; OBS (mean: $0.72 \mathrm{~mm} /$ day)
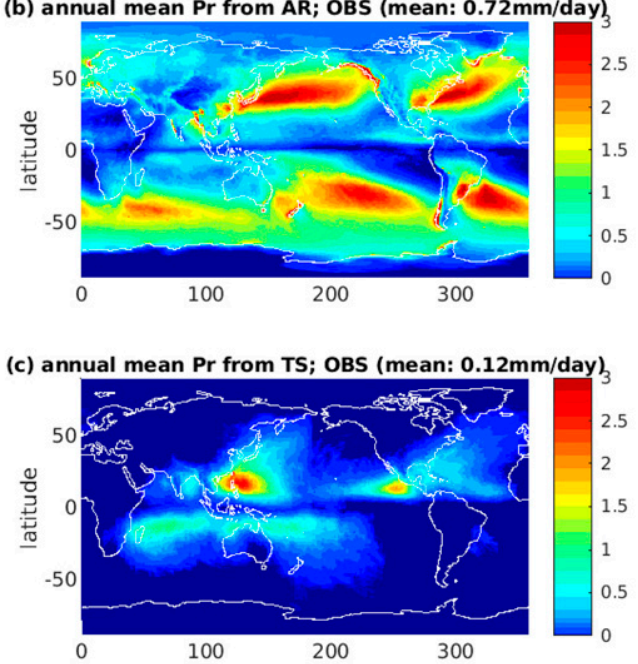

(d) annual mean Pr from MCS; OBS (mean: $0.69 \mathrm{~mm} /$ day)

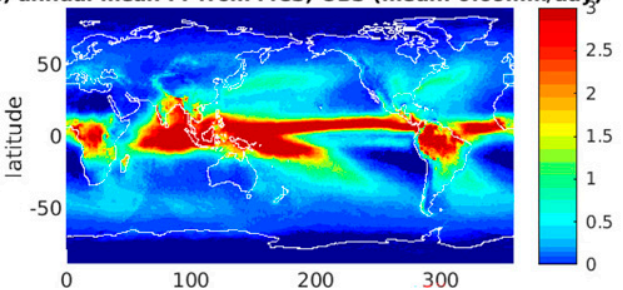

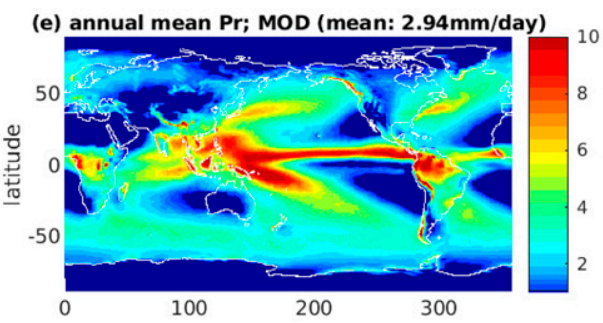
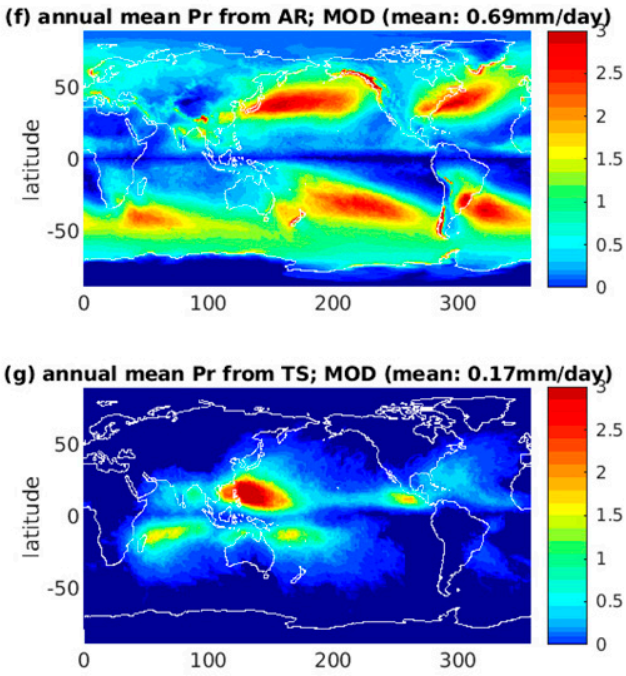

(h) annual mean Pr from MCS; MOD (mean: 0.74mm/day)

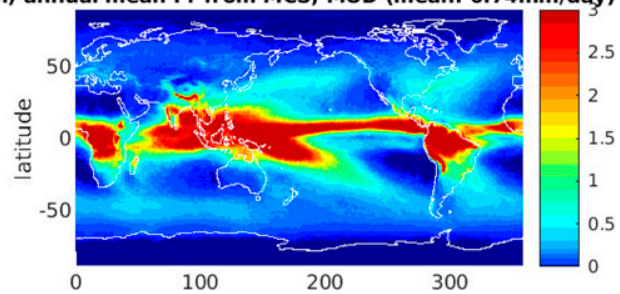

FIG. 2. (a) Geographical distribution of the observed annual mean precipitation rate $\left(\mathrm{mm} \mathrm{day}^{-1}\right)$ based on MSWEP-v2 precipitation dataset. (b)-(d) As in (a), but for the annual mean precipitation from AR, TS, and MCS days, respectively. The global area-weighted mean value is shown on the top of each panel. (e)-(h) As in (a)-(d), but for the model results from PRESENT.

sector, the model tends to slightly overestimate MCS frequency over the Caribbean Sea and underestimate them over the Great Plains in the United States. Many of these biases can be traced to the model's biases in tropical climatological precipitation and large-scale convective overturning motion instead of the MCS detection method used. Despite these regional biases, the modeled global annual frequency of MCS days $(4.37 \%)$ is remarkably close to the observational estimate $(4.28 \%)$

In general, the observed and modeled spatial distributions in annual frequency of AR/TS/MCS days are consistent with previous studies of AR/TS/MCS frequency (e.g., Guan and Waliser 2015; Jiang and Zipser 2010; Prat and Nelson 2013, 2016; Shaevitz et al. 2014; Huang et al. 2018; Feng et al. 2021) although these studies often define storm frequencies differently and one must take into account these differences when comparing them. For example, we define a calendar day as an AR/TS/MCS day for any given grid cell if at least one AR/TS/MCS condition is identified from the 6-hourly data during that calendar day. However, previous AR studies (e.g., Guan and Waliser 2015; Zhao 2020) used 6-hourly data to compute the frequency of AR conditions, which should yield smaller AR frequency than the frequency of AR days defined here. Indeed, when we used 6-hourly data to compute the AR frequency, we obtained the same results as in Guan and Waliser (2015) and Zhao (2020). For TS frequency, one also needs to take into account the differences in definitions of TS size (i.e., the surrounding area being impacted by a TS) when comparing the present study with previous studies. For example, we define the $12^{\circ} \times 12^{\circ}$ (lat $\times$ lon) region centered around each 6-hourly TS track location as the 

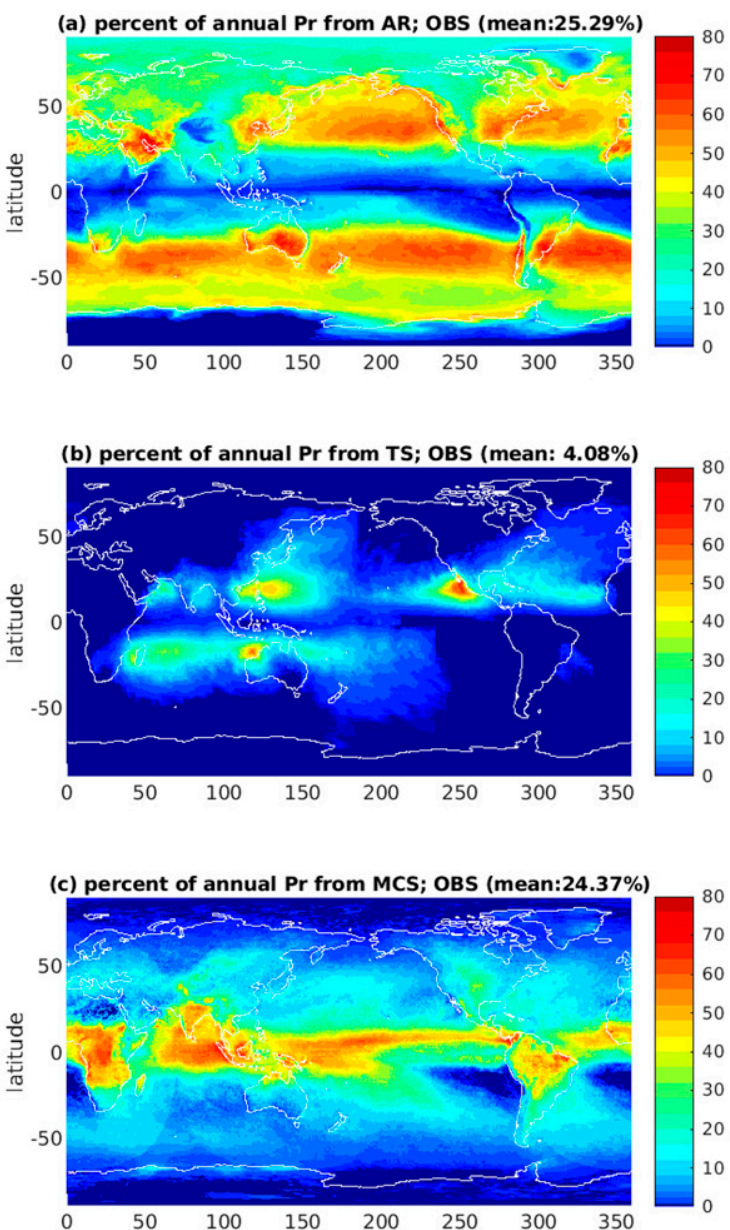
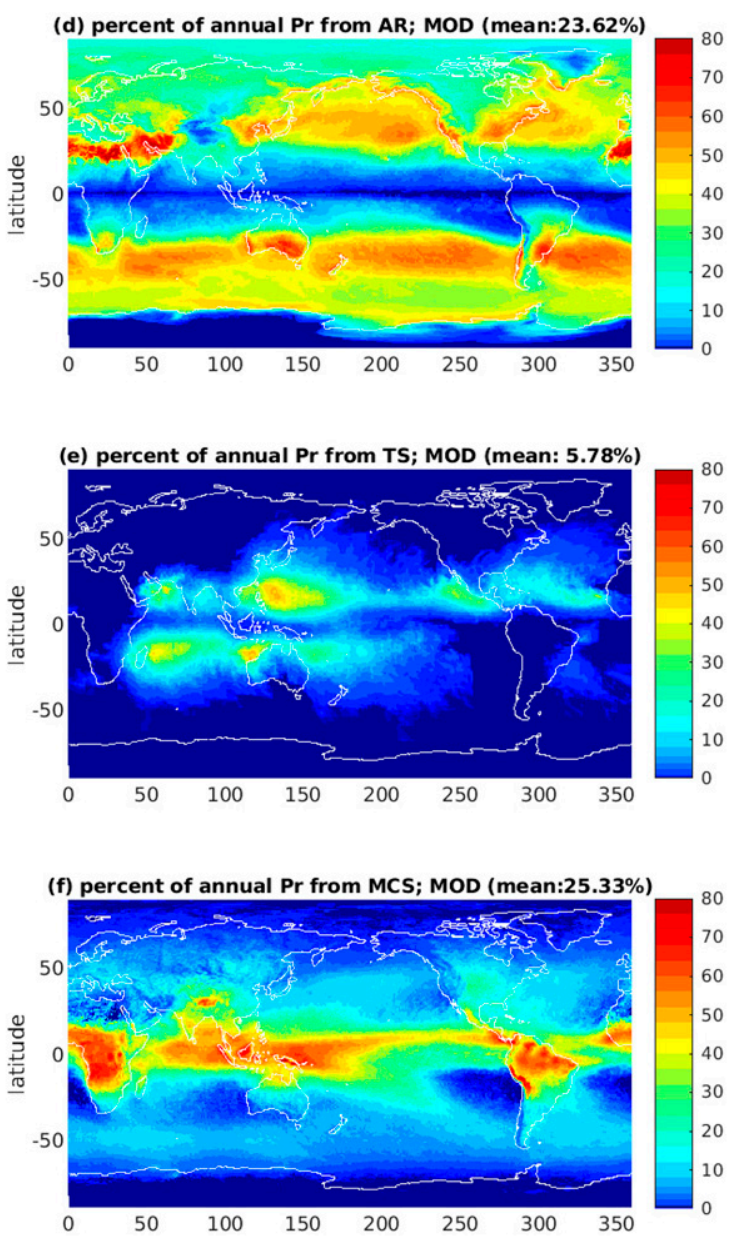

FIG. 3. (left) As in Figs. 2b-d, but for the percentage contribution of observed annual mean precipitation rate (\%) from (a) AR, (b) TS, and (c) MCS days. (d)-(f) As in (a)-(c), but for the model results from PRESENT.

area experiencing TS conditions while previous studies used TS track density on a certain number of grids [e.g., $1^{\circ} \times 1^{\circ}$ in Jiang and Zipser (2010) and $5^{\circ} \times 5^{\circ}$ in Shaevitz et al. (2014)] to measure annual TS frequency. These differences in computing annual TS frequency must be considered when comparing our results with the previous studies. In comparison with AR and TS studies, global-scale investigations of annual MCS frequency have been lacking especially for GCM studies due presumably to the models' deficiencies in simulating MCSs. Nevertheless, our model simulated annual frequency of MCS days compares reasonably well with the observational estimates (Fig. 1d) using an identical method for detecting MCS days as well as two recent observational studies that provided estimates of annual MCS frequency in the tropical (Huang et al. 2018) and $60^{\circ} \mathrm{S}-60^{\circ} \mathrm{N}$ regions (Feng et al. 2021).

Despite their occasional occurrence globally, Fig. 2 shows that the AR, TS, and MCS days together account for roughly $55 \%$ of the global annual mean precipitation in both the observations and the model. Individually, AR, TS, and MCS days account for respectively 25\% (24\%), 4.1\% (5.8\%), and $24 \%(25 \%)$ of the global mean precipitation in the observations (model). Regionally, AR-, TS-, and MCS-associated precipitation can each contribute up to $50 \%-60 \%$ of the local annual mean precipitation. For example, Fig. 3 shows that roughly $40 \%-60 \%$ of the annual precipitation over the $\mathrm{NH}$ and SH midlatitude storm track regions are from AR days. In parts of the eastern or western Pacific TC MDR regions, TSs can contribute up to $40 \%-50 \%$ their local annual precipitation. In many parts of the deep tropics, the MCS days account for $50 \%-60 \%$ of their annual precipitation. The model captures reasonably well the observed regional distribution of precipitation that is associated with AR, TS, and MCS days with a slight global underestimate (overestimate) of the AR (TS and MCS) precipitation. These results are also broadly in agreement with previous studies of AR/TS/MCSassociated precipitation using satellite observations (e.g., Jiang and Zipser 2010; Prat and Nelson 2013, 2016; Feng et al. 2021).

The AR-, TS-, and MCS-associated precipitation is essential for not only the geographical distribution of long-term mean precipitation but also the annual cycle and interannual variability of global mean daily precipitation. Figures $4 \mathrm{a}$ and $4 \mathrm{c}$ show 

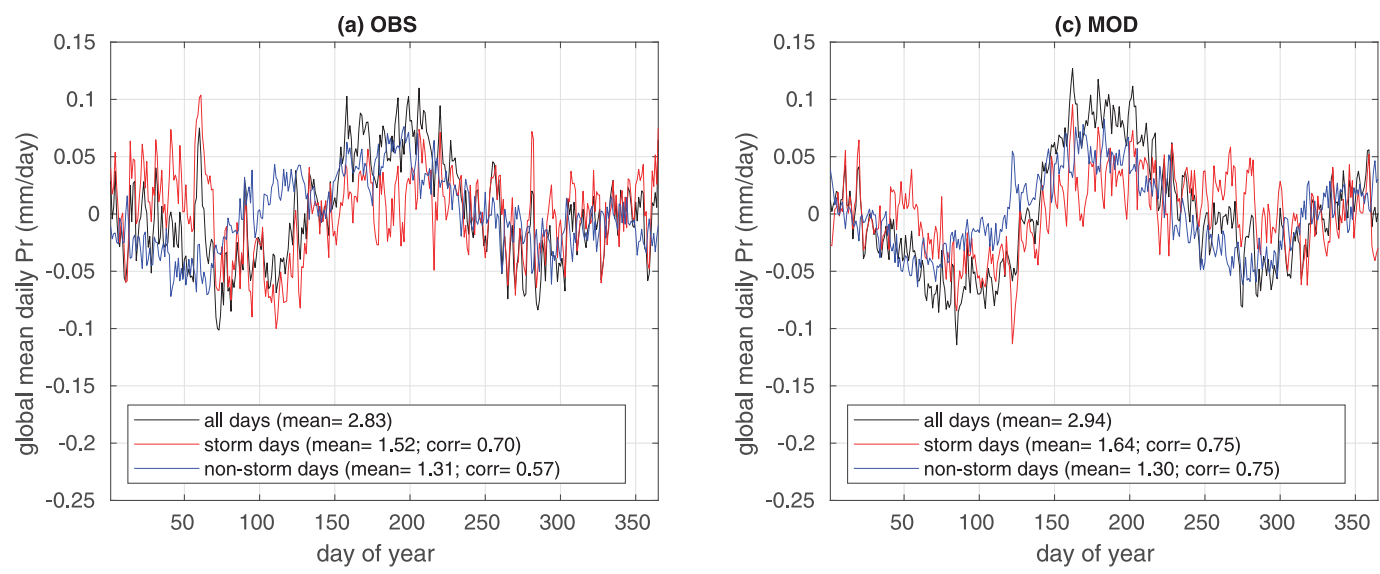

(b) OBS

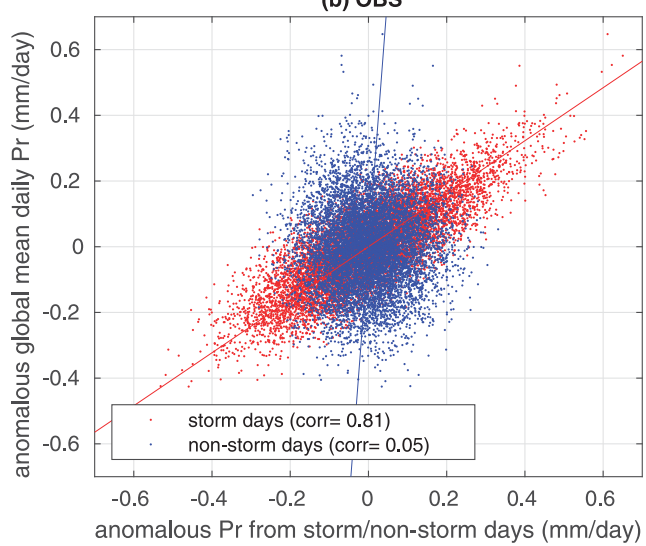

(d) MOD

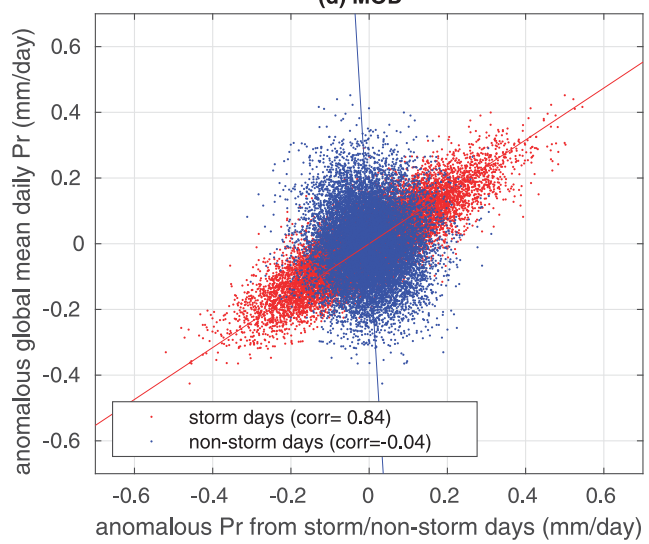

FIG. 4. (a) Observed (based on MSWEP-v2) climatological global mean daily precipitation rate (averaged over the 1979-2014 period) for each day of the year and its contributions from the storm (i.e., AR, TS, and MCS days together) and nonstorm days (i.e., all other days). Plotted are anomalies from their corresponding annual means, which are denoted in the legend. The legend also shows the correlation coefficient between storm/nonstorm day precipitation and total precipitation. (b) Scatterplots of the observed interannual anomalous global mean daily precipitation (ordinate) vs the interannual anomalous global mean daily precipitation from the (red dots) storm and (blue dots) nonstorm days (abscissa). The interannual anomalous precipitation is computed by subtracting the climatological values of daily precipitation [see (a)] from the global mean daily precipitation for each day over the 1979-2014 period. The correlation coefficients are denoted in the legend with the solid lines showing the orthogonal linear regressions. (c),(d) As in (a) and (b), but for the model results from PRESENT.

the observed and modeled climatological annual cycle of global mean daily precipitation, which is roughly equally affected by the storm days (i.e., AR, TS, and MCS together) and nonstorm days (i.e., the remaining days) with a correlation coefficient of $\sim 0.7$ between the total and storm-associated precipitation. Figures $4 \mathrm{~b}$ and $4 \mathrm{~d}$ further show that the interannual variation of global mean daily precipitation is dominated nearly entirely by storm days in both observations and the model. The correlation coefficient between the anomalous total precipitation and the anomalous precipitation associated with storm days is $0.81(0.84)$ in the observations (model). In contrast, we find no correlation between the anomalous total precipitation and the anomalous precipitation associated with nonstorm days.

To quantify the contribution of ARs, TSs, and MCSs to daily precipitation extremes, we present in Fig. 5 the geographical distribution of the 99th percentile of daily precipitation rate and the occurrence frequency of the daily precipitation that exceeds the 99th percentile locally from the AR, TS, and MCS days for both observations and the model. Compared to the observations, the model tends to produce higher 99th percentile values of daily precipitation over the deep tropics, especially tropical Africa. Despite the model's systematical bias, it well reproduces the observed frequency of extreme daily precipitation (i.e., daily precipitation exceeding the 99th percentile) associated with AR, TS, and MCS days at both regional and global scales. Globally, the AR, TS, and MCS days together account for roughly $75 \%$ of extreme precipitation in both observations $(76.7 \%)$ and the model simulation $(74.3 \%)$. Regionally, these weather phenomena together account for $80 \%-100 \%$ of extreme daily precipitation over most parts of the world. The 
(a) 99 percentile of daily $\mathrm{Pr}$; OBS (mean: $25.51 \mathrm{~mm} /$ day)
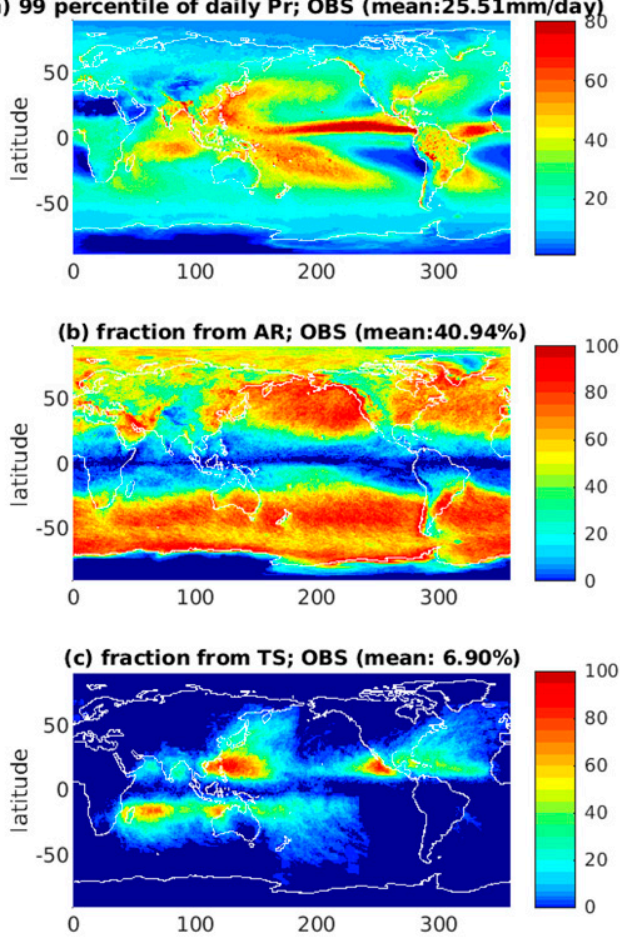

(d) fraction from MCS; OBS (mean:28.88\%)

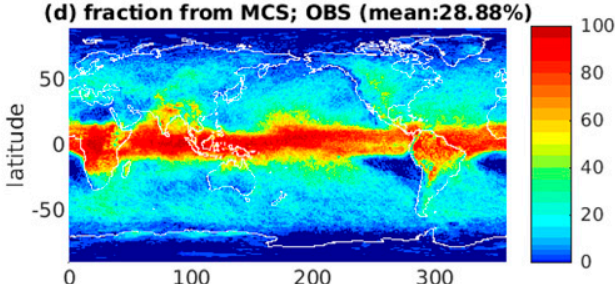

(e) 99 percentile of daily Pr; MOD (mean:31.45mm/day)
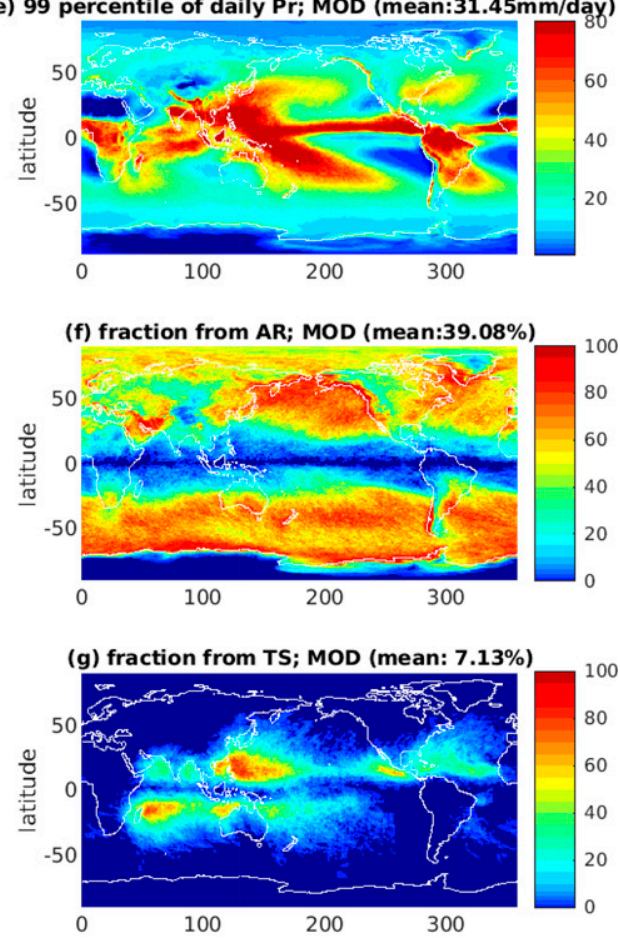

(h) fraction from MCS; MOD (mean:28.12\%)

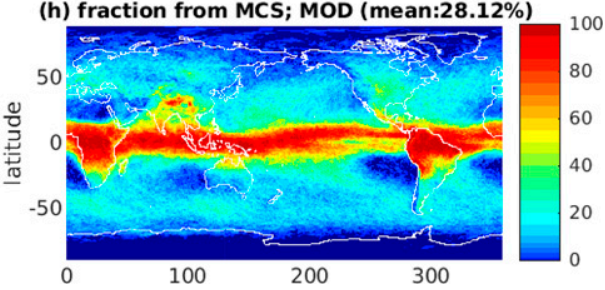

FIG. 5. (a) Geographical distribution of the 99th percentile of observed daily precipitation rates $\left(\mathrm{mm} \mathrm{day}^{-1}\right)$ based $^{-1}$ on MSWEP-v2 precipitation dataset. (b)-(d) As in (a), but for the occurrence frequency (\%) of daily precipitation that exceeds the 99th percentile [see (a)] locally from AR, TS, and MCS days, respectively. The global area-weighted mean value is shown on the top of each panel. (e)-(h) As in (a)-(d), but for the model results from PRESENT.

exceptions are typically regions where the precipitation 99th percentile is low (see the blue colored regions in Figs. 5a,e), including parts of the subsiding branch of Hadley and Walker circulations and the polar regions. Thus, Fig. 5 reveals the essential role of ARs, TSs, and MCSs in generating disastrous extreme precipitation around the globe, consistent with many previous studies (e.g., Lavers and Villarini 2013, 2015; Prat and Nelson 2013, 2016; Houze 2018; Feng et al. 2021).

However, it should be emphasized that not all AR/TS/MCS days are equal. Figures $6-8$ show respectively the daily precipitation rate averaged over all, the $25 \%$ heaviest precipitation, and the $25 \%$ lightest precipitation AR, TS, and MCS days from observations and the model. The model tends to overestimate the AR-, TS-, and MCS-associated mean and heavier precipitation and underestimate their associated weaker precipitation (see also Table 1). Despite this model bias, both the model and the observations show that the average precipitation of the $25 \%$ heaviest precipitation days are about 2-3 times larger than their mean precipitation and 10-20 times larger than the average of the $25 \%$ lightest precipitation days. Table 1 further reveals that more than $88 \%$ (67\%) of the total TS precipitation comes from their 50\% (25\%) heaviest precipitation days, which is true for both observations and the model. For AR and MCS days, the percentages are lower; in particular, more than $82 \%(58 \%)$ of AR-associated and $77 \%(52 \%)$ of MCS-associated precipitation results from their corresponding $50 \%(25 \%)$ heaviest precipitation days. This suggests that the distribution of daily precipitation among the AR, TS, and MCS days is strongly positively skewed, with their $25 \%$ heaviest precipitation days playing the dominant role in both mean and extreme precipitation in the present climate.

In general, the model's quality in simulating AR-, TS-, and MCS-associated precipitation in the present climate justifies its use for exploring possible changes in AR/TS/MCS-associated mean and extreme precipitation in a warmer climate. Below we present the model results derived from the pair of $100-\mathrm{yr}$ 

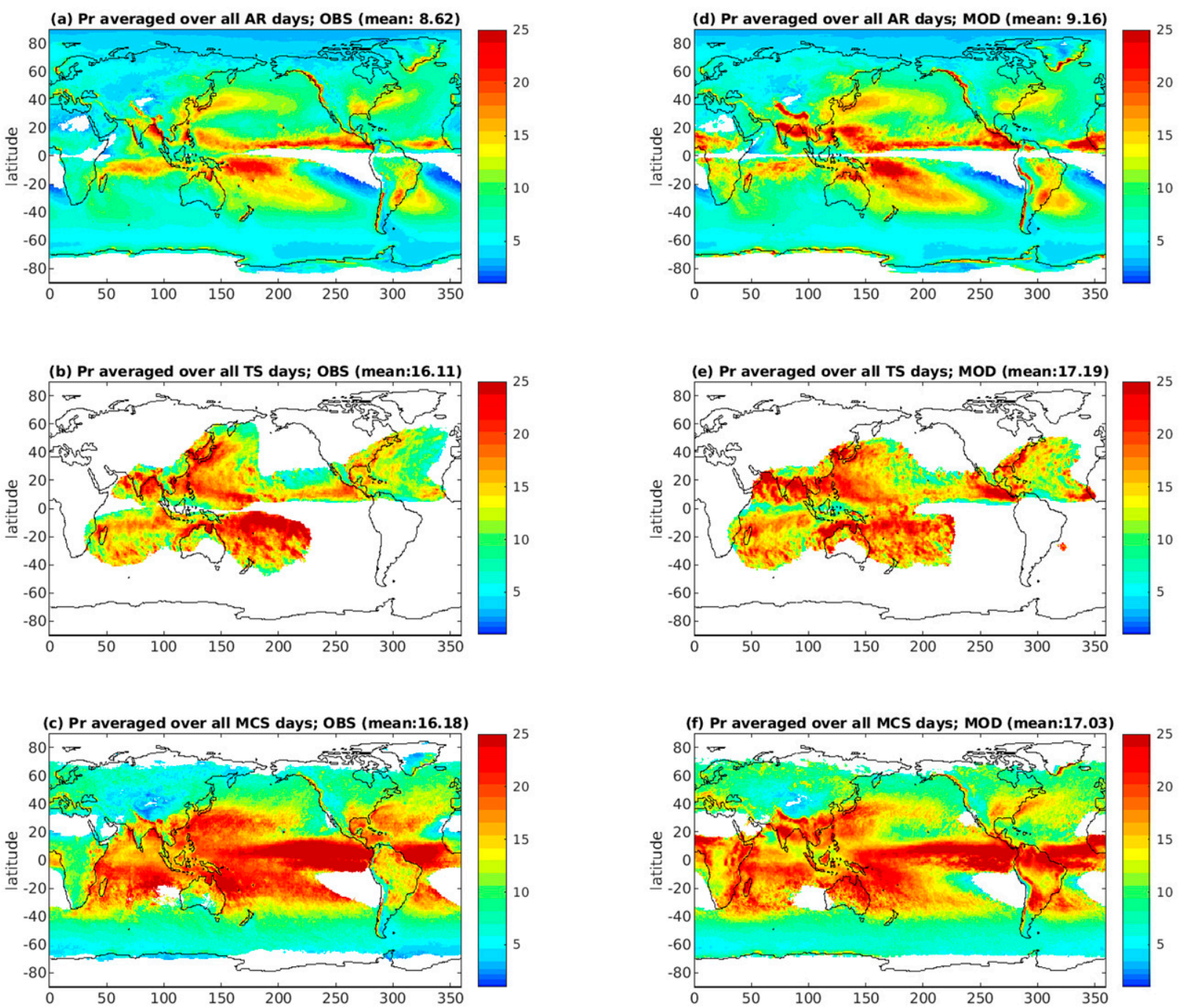

FIG. 6. Geographical distribution of the observed daily precipitation rate $\left(\mathrm{mm} \mathrm{day}^{-1}\right)$ averaged over all (a) AR, (b) TS, and (c) MCS days. Grid cells with total number of AR/TS/MCS days less than 30 are masked out. The AR/TS/MCS frequency-weighted global mean precipitation from all AR/TS/MCS days-that is, $\left[\overline{P_{r, \text { all } X}}\right]=\int_{y} \int_{x} \overline{P_{r, \text { all } X}}(x, y) F_{\text {all } X}(x, y) d x d y / \int_{y} \int_{x} F_{\text {all } X}(x, y) d x d y$, where $X=\operatorname{AR} / \mathrm{TS} / \mathrm{MCS}$ days, and $\overline{P_{r, \text { all } X}}$ and $F_{\text {all } X}$ denote respectively the mean precipitation and frequency averaged from all AR/TS/MCS days at each location $(x, y)$-is shown on the top of each panel. (d)-(f) As in (a)-(c), but for the model results from PRESENT.

simulations using CLIMO and P4K. The use of CLIMO and P4K allows us to focus on the effect of global mean SST warming without worrying about future changes in SST variability (both spatial patterns and temporal variations) and other forcing agents, which are highly uncertain compared to the global mean warming. It also helps to improve the model's statistics in extreme precipitation because the simulations do not contain interannual variability of forcings and each year can be considered as an independent sample from the present or warmer climate. The AR, TS, and MCS frequency and their associated precipitation in CLIMO are generally very similar to PRESENT described above. Table 1 includes a detailed comparison of the global frequency of AR/TS/MCS days and their associated precipitation between PRESENT and CLIMO.

\section{Changes in AR/TS/MCS precipitation in a warmer climate}

To explore the precipitation response to global warming we show in Fig. 9 the geographical distribution of the changes in annual mean precipitation rate and its contributions from the AR, TS, and MCS days. Globally, the model produces roughly a $2.85 \% \mathrm{~K}^{-1}$ increase in global mean precipitation, of which roughly $67 \%$ comes from the AR, TS, and MCS days collectively. The significantly larger increase in global 
(a) Pr averaged over 25\% heaviest-Pr AR days; OBS (mean:19.93)

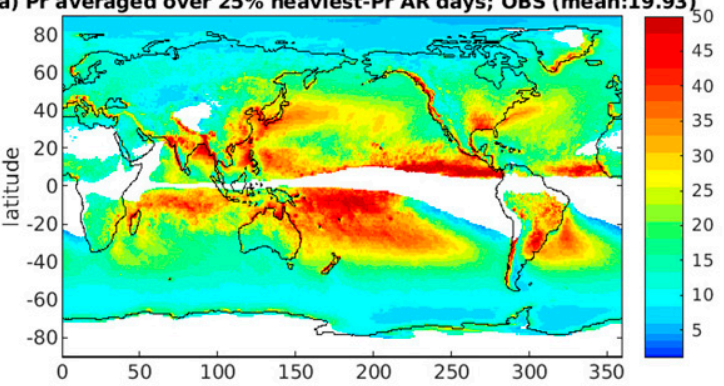

(b) Pr averaged over 25\% heaviest-Pr TS days; OBS (mean:43.37)

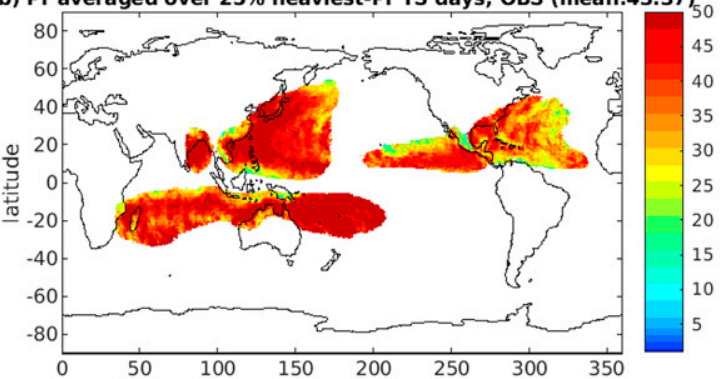

(c) Pr averaged over 25\% heaviest-Pr MCS days; OBS (mean:33.43)

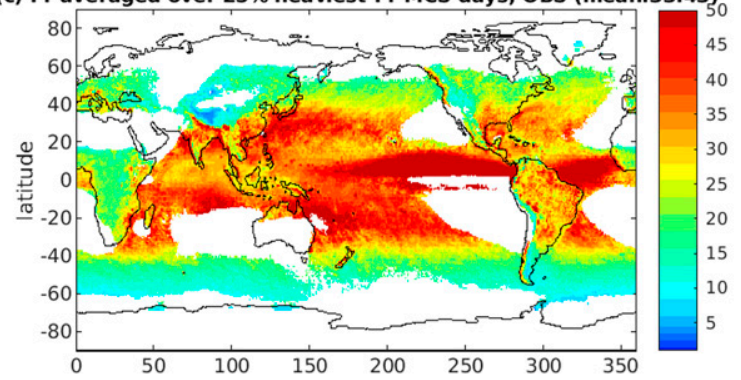

(d) Pr averaged over 25\% heaviest-Pr AR days; MOD (mean:22.09)

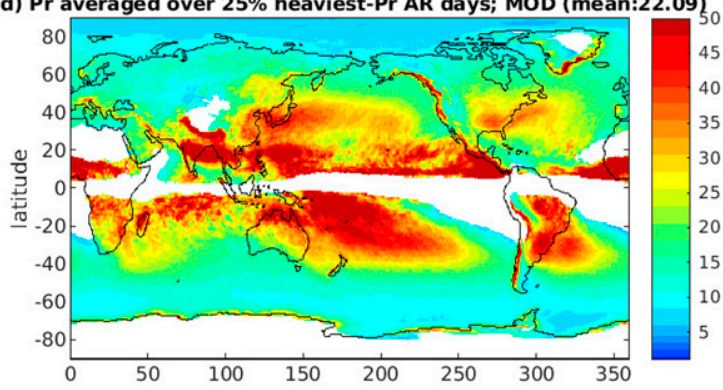

(e) Pr averaged over 25\% heaviest-Pr TS days; MOD (mean:50.02)

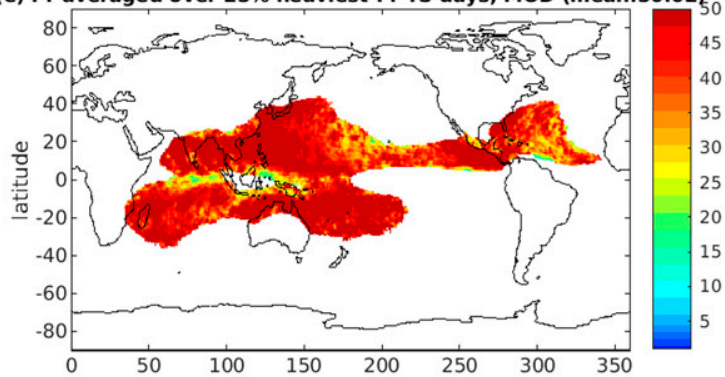

(f) Pr averaged over 25\% heaviest-Pr MCS days; MOD (mean:43.13)

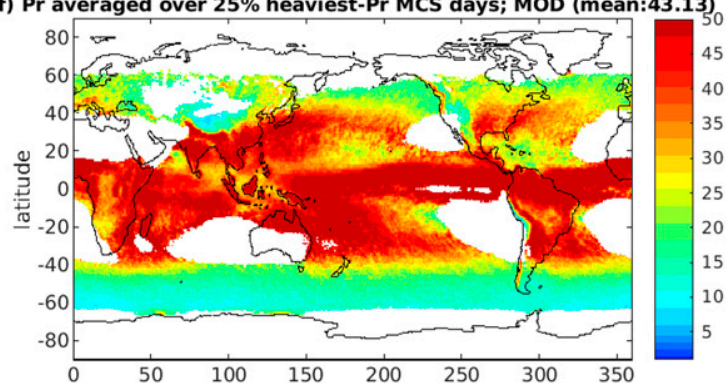

FIG. 7. As in Fig. 6, but for daily precipitation rate averaged over the local $25 \%$ heaviest precipitation AR, TS, and MCS days.

mean precipitation compared to the typical values $(\sim 2 \%$ $\mathrm{K}^{-1}$ ) seen in coupled simulations (Held and Soden 2006) is because we did not increase the atmospheric $\mathrm{CO}_{2}$ concentration in the $\mathrm{P} 4 \mathrm{~K}$ warming experiment. A doubling of the atmospheric $\mathrm{CO}_{2}$ concentration without changing SSTs will produce a significant reduction of global mean precipitation due to a reduced atmospheric cooling rate. This is often referred to as the direct effect of $\mathrm{CO}_{2}$ as opposed to its effect on SSTs in coupled simulations (Held and Zhao 2011; Bony et al. 2013). Individually, the AR-, TS-, and MCS-associated global mean precipitation increases by $5.44 \%, 1.47 \%$, and $2.03 \% \mathrm{~K}^{-1}$ respectively (see Table 1 ). These global and annual mean increases in precipitation are produced by their changes in both frequency and intensity in precipitation. Regionally, the spatial distribution of changes in annual mean precipitation is also well captured by the total changes in AR-, TS-, and MCS-associated precipitation with the net changes being dominated by the AR days in the middle and high latitudes and by the TS and MCS days in the tropical and subtropical regions.

To understand the regional change in AR-, TS-, and MCSassociated precipitation, Fig. 10 shows the changes in frequency of AR/TS/MCS days (Figs. 10a-c) as well as the changes in mean precipitation averaged over all AR/TS/MCS days (Figs. 10d-f). Except for TS-associated precipitation in the equatorial northwestern Pacific near the Philippine Sea, the spatial patterns of changes in AR/TS/MCS-associated annual precipitation appears to correlate well with their changes in annual frequency. Globally, the frequency of AR days increases slightly by $1.22 \% \mathrm{~K}^{-1}(0.093 \% / 7.6 \%)$ while the frequency of TS and MCS days decreases by $2.86 \% \mathrm{~K}^{-1}$ $(-0.027 \% / 0.96 \%)$ and $2.05 \% \mathrm{~K}^{-1}(-0.099 / 4.64)$ respectively (see Table 1 for more details). Regionally, the maximum frequency of AR days tends to migrate poleward while the frequency of TS days tends to increase over the central Pacific and part of the south Indian Ocean with a decrease elsewhere. 


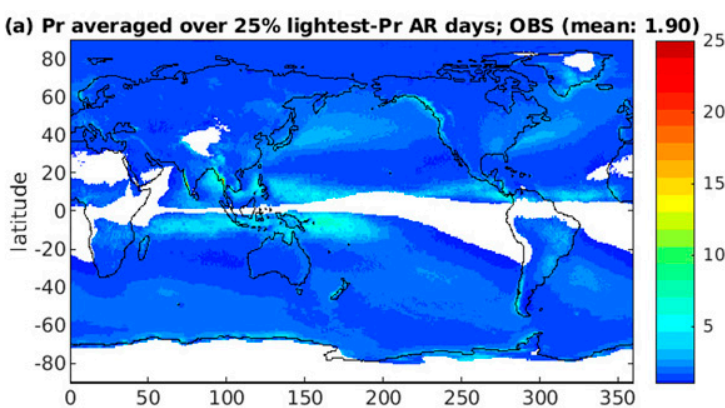

(b) Pr averaged over 25\% lightest-Pr TS days; OBS (mean: 2.13) 25

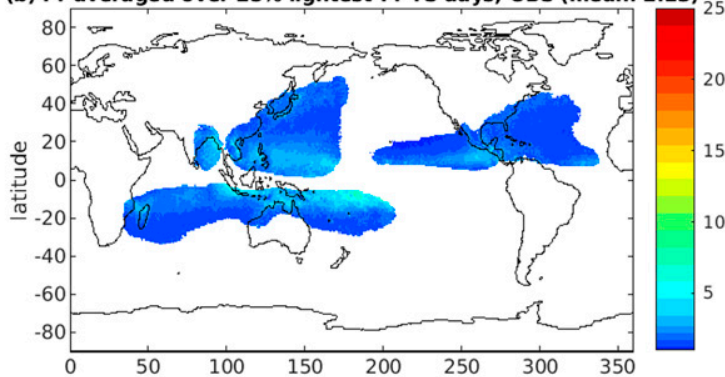

(c) Pr averaged over 25\% lightest-Pr MCS days; OBS (mean: 4.95 )

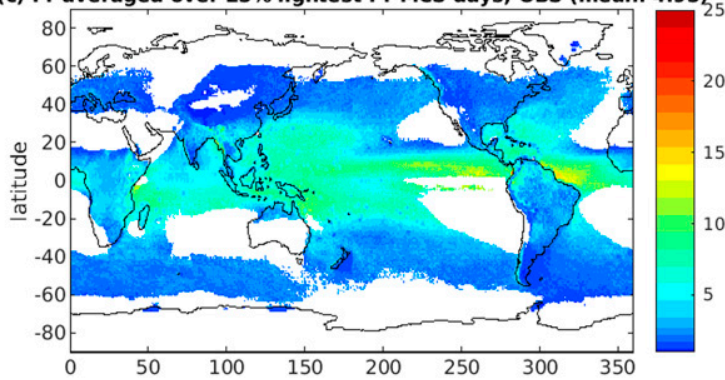

(d) Pr averaged over 25\% lightest-Pr AR days; MOD (mean: 1.84)

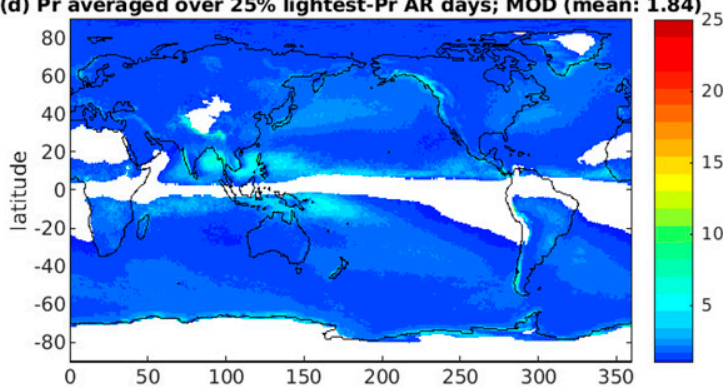

(e) Pr averaged over 25\% lightest-Pr TS days; MOD (mean: 1.97)

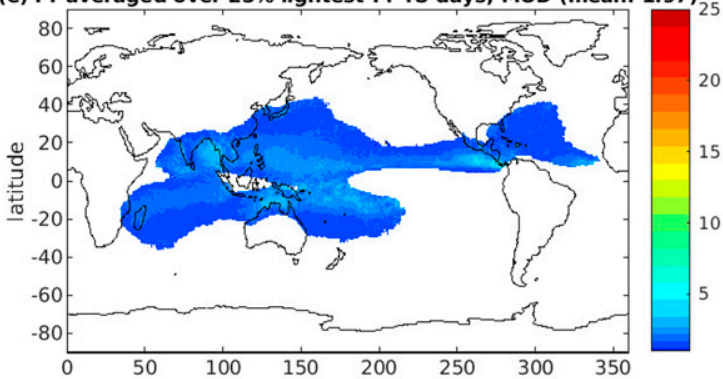

(f) Pr averaged over 25\% lightest-Pr MCS days; MOD (mean: 2.93)

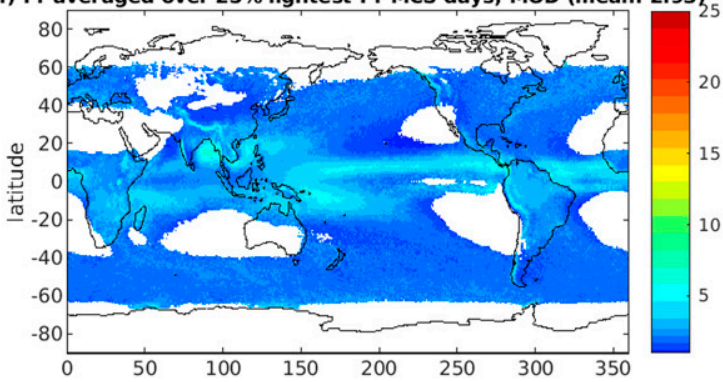

FIG. 8. As in Fig. 6, but for daily precipitation rate averaged over the local 25\% lightest precipitation AR, TS, and MCS days.

The frequency of MCS days tends to increase over parts of the equatorial western and eastern Pacific warm pools and high latitudes and decrease over most parts of the tropics and subtropics, with the largest reduction over the tropical landcovered regions.

While the general increase in global occurrence frequency of AR conditions in warmer climates is consistent with previous studies (e.g., Espinoza et al. 2018), Zhao (2020) pointed out that the increase in previous studies is likely to be significantly overestimated due to their use of the historical IVT threshold for detecting ARs in warmer climates. This will impact AR-associated precipitation. The global reduction in TS frequency with warming has been reported in many previous studies (e.g., Knutson et al. 2010, 2020). However, regional changes in TS frequency remain highly uncertain. For example, Villarini and Vecchi (2012) pointed out large uncertainties in twenty-first-century projection of North Atlantic (NA) TS frequency due to model uncertainties in projecting future SST warming patterns, especially the relative SST warming over the tropical Atlantic (defined as the difference between tropical Atlantic and tropical mean SST warming). Because of the limitations of $\mathrm{P} 4 \mathrm{~K}$, which is designed to simulate only the effects of global mean SST warming, one must be cautious about comparing regional changes in storm frequency between the present study and either future projections or any observed trends, which may be affected by SST warming patterns as well as changes in forcing agents. For example, Feng et al. (2016) found an increase in springtime total and extreme rainfall in the central United States over recent decades, which was dominated by MCSs, while our model shows a reduction in annual frequency of MCS days over the United States in response to global uniform warming. It is however unclear if the observed increase in springtime MCS is due to global mean SST warming, a specific warming pattern, or changes in forcing agents during this period. It is also unclear if the observed increase in MCS still exists when averaged over the entire year. An investigation of these differences is beyond the scope of the present paper. 
TABLE 1. Global annual frequency of AR/TS/MCS days and their associated precipitation from observations and the model's PRESENT, CLIMO, and P4K simulations; $\left[\overline{P_{r}}\right]$ denotes global annual mean precipitation (mm day ${ }^{-1}$ ), which is followed by its contributions from AR/TS/MCS days with the numbers in parentheses indicating the percentage of $\left[\overline{P_{r}}\right]$ from AR/TS/MCS days. Also, $\left[\overline{P_{r, \text { all } X}}\right]\left(X=\right.$ AR/TS/MCS days) denotes AR/TS/MCS frequency weighted global mean precipitation rate $\left(\mathrm{mm} \mathrm{day}^{-1}\right)$ from all AR/TS/MCS days (see Fig. 6 caption for definition). Similarly, $\left[\overline{P_{r, h 25 X}}\right],\left[\overline{P_{r, h 50 X}}\right],\left[\overline{P_{r, l 50 X}}\right]$, and $\left[\overline{P_{r, l 25 X}}\right]$ denote respectively the $\mathrm{AR} / \mathrm{TS} / \mathrm{MCS}$ frequency weighted global mean precipitation rate $\left(\mathrm{mm} \mathrm{day}^{-1}\right)$ averaged over the $25 \%, 50 \%$ heaviest precipitation, and the $50 \%, 25 \%$ lightest precipitation AR/TS/MCS days with the numbers in parentheses indicating the percentage of total AR/TS/MCS precipitation coming from each category of the AR/TS/MCS days.

\begin{tabular}{|c|c|c|c|c|c|}
\hline & Observations & PRESENT & CLIMO & $\mathrm{P} 4 \mathrm{~K}$ & $(\mathrm{P} 4 \mathrm{~K}-\mathrm{CLIMO}) / \mathrm{CLIMO} / \Delta T_{s}$ \\
\hline Frequency of AR + TS + MCS days & $13.55 \%$ & $13.08 \%$ & $13.20 \%$ & $13.06 \%$ & $-0.26 \% \mathrm{~K}^{-1}$ \\
\hline Frequency of AR days & $8.33 \%$ & $7.58 \%$ & $7.60 \%$ & $8.02 \%$ & $1.22 \% \mathrm{~K}^{-1}$ \\
\hline Frequency of TS days & $0.72 \%$ & $0.99 \%$ & $0.96 \%$ & $0.83 \%$ & $-2.86 \% \mathrm{~K}^{-1}$ \\
\hline Frequency of MCS days & $4.28 \%$ & $4.37 \%$ & $4.64 \%$ & $4.21 \%$ & $-2.05 \% \mathrm{~K}^{-1}$ \\
\hline$\left[\overline{P_{r}}\right]\left(\mathrm{mm} \mathrm{day}^{-1}\right)$ & 2.84 & 2.94 & 2.94 & 3.32 & $2.85 \% \mathrm{~K}^{-1}$ \\
\hline$\left[\overline{P_{r}}\right]$ from $\mathrm{AR}+\mathrm{TS}+\mathrm{MCS}$ days & $1.53(53.8 \%)$ & $1.60(54.7 \%)$ & $1.61(54.8 \%)$ & $1.86(56.0 \%)$ & $3.43 \% \mathrm{~K}^{-1}$ \\
\hline$\left[\overline{P_{r}}\right]$ from AR days & $0.72(25.3 \%)$ & $0.69(23.6 \%)$ & $0.69(23.5 \%)$ & $0.86(25.9 \%)$ & $5.44 \% \mathrm{~K}^{-1}$ \\
\hline$\left[\overline{P_{r}}\right]$ from TS days & $0.12(4.1 \%)$ & $0.17(5.8 \%)$ & $0.15(5.1 \%)$ & $0.16(4.8 \%)$ & $1.47 \% \mathrm{~K}^{-1}$ \\
\hline$\left[\overline{P_{r}}\right]$ from MCS days & $0.69(24.4 \%)$ & $0.74(25.3 \%)$ & $0.76(25.9 \%)$ & $0.83(25.0 \%)$ & $2.03 \% \mathrm{~K}^{-1}$ \\
\hline$\left[\overline{P_{r, \text { all } X}}\right](X=$ AR days $)$ & 8.62 & 9.16 & 9.05 & 10.7 & $4.02 \% \mathrm{~K}^{-1}$ \\
\hline$\left[\overline{\left.P_{r, \text { all } X}\right]}\right.$ ( $X=$ TS days $)$ & 16.1 & 17.2 & 15.8 & 19.5 & $5.17 \% \mathrm{~K}^{-1}$ \\
\hline$\left[\overline{\left.P_{r, \text { all } X}\right]}\right.$ ( $X=$ MCS days $)$ & 16.2 & 17.0 & 16.0 & 19.4 & $4.69 \% \mathrm{~K}^{-1}$ \\
\hline$\left[\overline{P_{r, h 25 X}}\right](X=$ AR days $)$ & $19.93(58 \%)$ & $22.09(60 \%)$ & $21.76(60 \%)$ & $26.61(62 \%)$ & $4.92 \% \mathrm{~K}^{-1}$ \\
\hline$\left[\overline{P_{r, h 25 X}}\right]$ ( $X=$ TS days $)$ & $43.37(67 \%)$ & $50.02(73 \%)$ & $45.53(72 \%)$ & $57.83(74 \%)$ & $5.96 \% \mathrm{~K}^{-1}$ \\
\hline$\left[\overline{P_{r, h 25 X}}\right](X=$ MCS days $)$ & $33.43(52 \%)$ & $43.13(63 \%)$ & $40.01(63 \%)$ & $51.02(66 \%)$ & $6.07 \% \mathrm{~K}^{-1}$ \\
\hline$\left[P_{r, h 50 X}\right](X=$ AR days $)$ & $14.13(82 \%)$ & $15.28(83 \%)$ & $15.06(83 \%)$ & $18.07(85 \%)$ & $4.41 \% \mathrm{~K}^{-1}$ \\
\hline$\left[\overline{P_{r, h 50 X}}\right](X=$ TS days $)$ & $28.33(88 \%)$ & $30.89(90 \%)$ & $28.15(89 \%)$ & $35.24(90 \%)$ & $5.56 \% \mathrm{~K}^{-1}$ \\
\hline$\left[P_{r, h 50 X}\right](X=$ MCS days $)$ & $24.86(77 \%)$ & $28.85(85 \%)$ & $26.93(84 \%)$ & $33.53(86 \%)$ & $5.41 \% \mathrm{~K}^{-1}$ \\
\hline$\left[\overline{P_{r, l 50 X}}\right]$ (X= AR days $)$ & $3.11(18 \%)$ & $3.05(17 \%)$ & $3.04(17 \%)$ & $3.26(15 \%)$ & $1.60 \% \mathrm{~K}^{-1}$ \\
\hline$\left[\overline{P_{r, l 50 X}}\right](X=$ TS days $)$ & $3.93(12 \%)$ & $3.54(10 \%)$ & $3.36(11 \%)$ & $3.80(10 \%)$ & $2.89 \% \mathrm{~K}^{-1}$ \\
\hline$\left[P_{r, l 50 X}\right]$ (X= MCS days $)$ & $7.53(23 \%)$ & $5.22(15 \%)$ & $5.14(16 \%)$ & $5.26(14 \%)$ & $0.52 \% \mathrm{~K}^{-1}$ \\
\hline$\left[\overline{P_{r, l 25 X}}\right](X=$ AR days $)$ & $1.90(5.5 \%)$ & $1.84(5.0 \%)$ & $1.84(5.1 \%)$ & $1.91(4.5 \%)$ & $0.84 \% \mathrm{~K}^{-1}$ \\
\hline$\left[\overline{P_{r, l 25 X}}\right](X=$ TS days $)$ & $2.13(3.3 \%)$ & $1.97(2.9 \%)$ & $1.93(3.1 \%)$ & $2.10(2.7 \%)$ & $1.94 \% \mathrm{~K}^{-1}$ \\
\hline$\left[\overline{P_{r, l 25 X}}\right]$ (X = MCS days $)$ & $4.95(7.6 \%)$ & $2.93(4.3 \%)$ & $2.96(4.6 \%)$ & $2.86(3.7 \%)$ & $-0.75 \% \mathrm{~K}^{-1}$ \\
\hline
\end{tabular}

To quantify the change in AR/TS/MCS precipitation intensity with global warming, Figs. 10d-f show the percentage changes in daily precipitation rate averaged over all AR/TS/MCS days. Note that the regions with the total number of AR/TS/MCS days less than 30 in CLIMO or $\mathrm{P} 4 \mathrm{~K}$ and the regions where the precipitation changes are not statistically significant at a $95 \%$ confidence level (based on $Z$ tests) are masked out. There is a broad increase in AR/TS/MCS precipitation intensity around the globe, which is in sharp contrast with the changes in AR/TS/MCS frequency, which exhibit regions of increases or decrease with similar magnitudes. We may compute global mean change in AR/ TS/MCS precipitation intensity in two different ways. The first is a simple global area-weighted mean over AR/TS/MCS regions, which are respectively $4.75 \%, 8.67 \%$, and $5.19 \% \mathrm{~K}^{-1}$ for $\mathrm{AR}$, TS, and MCS days. The second is the percentage change in AR/ TS/MCS frequency weighted global mean precipitation from all AR/TS/MCS days-that is, the percentage change in $\left[\overline{P_{r, \text { all } X}}\right]=\int_{y} \int_{x} \overline{P_{r, \text { all } X}}(x, y) F_{\text {all } X}(x, y) d x d y / \int_{y} \int_{x} F_{\text {all } X}(x, y) d x d y$, where $X=\mathrm{AR} / \mathrm{TS} / \mathrm{MCS}$ days and $\overline{P_{r \text {,all } X}}$ and $F_{\text {all } X}$ denote respectively the mean precipitation and frequency averaged from all AR/ TS/MCS days at each location $(x, y)$-which yields respectively $3.94 \%, 5.27 \%$, and $4.63 \% \mathrm{~K}^{-1}$ for all AR, TS, and MCS days.
The increases in AR/TS/MCS mean precipitation are due primarily to the changes in its $25 \%$ heaviest precipitation days. To illustrate this, Fig. 11 shows the percentage changes in the $25 \%$ heaviest precipitation as well as the $25 \%$ lightest precipitation AR/TS/MCS days between P4K and CLIMO. The $25 \%$ heaviest precipitation AR, TS, and MCS days generally display a similar or larger percentage increase in precipitation intensity compared to the change of AR/TS/MCS mean precipitation with slightly larger global mean values (see the numbers on the top of each panel). In contrast, the $25 \%$ lightest precipitation AR, TS, and MCS days exhibit a much smaller increase or even a decrease in many regions. The global area-weighted (frequency-weighted) mean are respectively $0.37 \%(0.83 \%), 2.4 \% \quad(1.97 \%)$, and $-0.6 \%$ $(-0.73 \%) \mathrm{K}^{-1}$ for these AR, TS, and MCS days. Thus, this result suggests a change in the character of storm-associated precipitation in response to global warming with heavy precipitation becoming heavier while weak precipitation remains relatively unchanged.

Since the $25 \%$ heaviest precipitation AR/TS/MCS days tend to dominate the response of both mean and extreme precipitation in warmer climates below we try to understand their response through the changes in their dynamic, thermodynamic, 

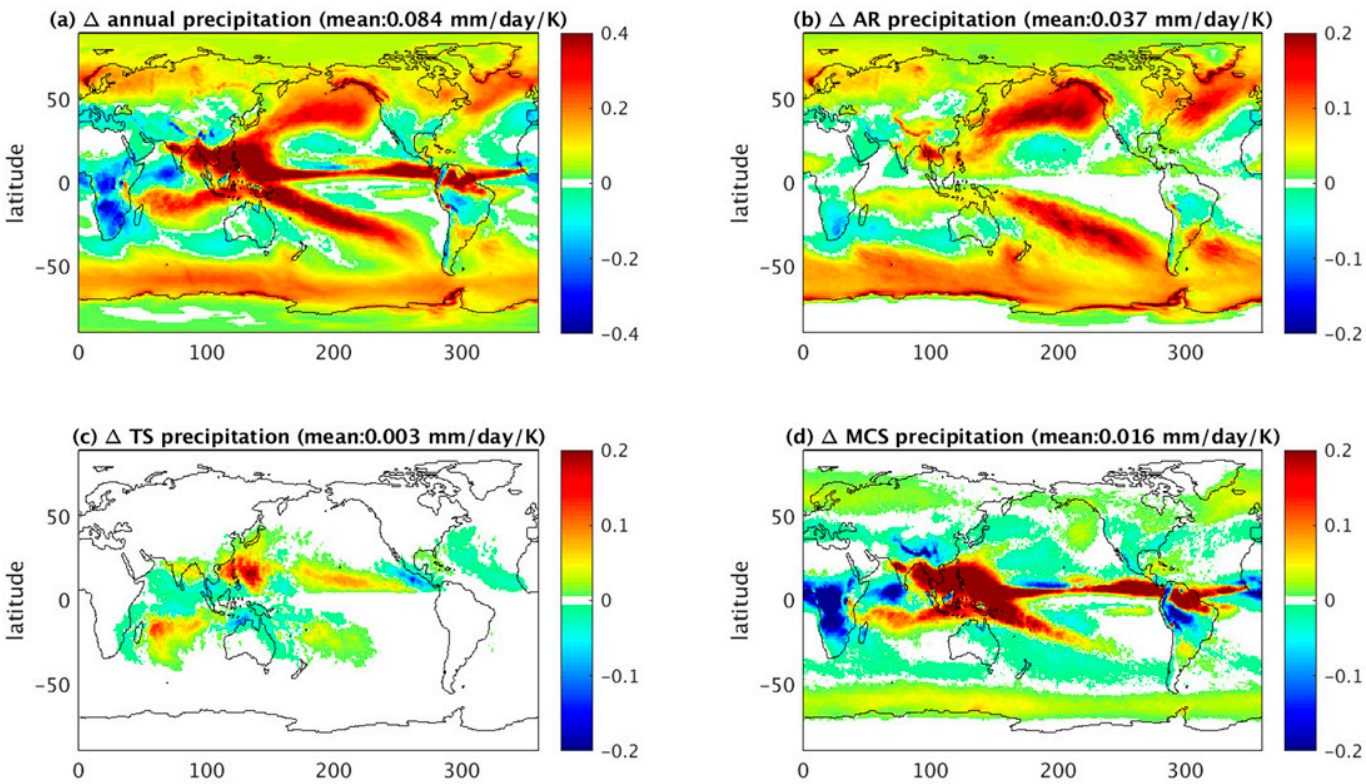

FIG. 9. (a) Geographical distribution of changes in annual mean precipitation rate normalized to per 1 degree global mean surface air temperature warming $\left(\mathrm{mm} \mathrm{day}^{-1} \mathrm{~K}^{-1}\right.$, global mean surface air temperature warming $\Delta T_{G}=$ $4.53 \mathrm{~K}$ ) between P4K and CLIMO. (b)-(d) As in (a), but for the changes in precipitation from all AR, TS, and MCS days, respectively. The global area-weighted mean value is shown on the top of each panel.

and microphysical environments in response to global warming. The dependence of storm-associated precipitation may be approximated by the following relationship (Muller and Takayabu 2020):

$$
P_{r} \propto-\epsilon \omega_{500} q_{850},
$$

where $P_{r}$ represents AR/TS/MCS-associated precipitation, $\omega_{500}$ denotes the vertical pressure velocity at $500 \mathrm{hPa}, q_{850}$ is low-level specific humidity at $850 \mathrm{hPa}$, and $\epsilon$ is precipitation efficiency. The percentage change of $P_{r}$ may then be understood through the following decomposition:

$$
\frac{\delta P_{r}}{P_{r}} \approx \frac{\delta \omega_{500}}{\omega_{500}}+\frac{\delta q_{850}}{q_{850}}+\frac{\delta \epsilon}{\epsilon},
$$

where the terms on the RHS of Eq. (4) represent the percentage changes in $P_{r}$ due to the dynamic $\left(\delta \omega_{500}\right)$, thermodynamic $\left(\delta q_{850}\right)$, and microphysical $(\delta \epsilon)$ components. Figures $12 \mathrm{a}-\mathrm{c}$ show the geographical distribution of the percentage changes in $\omega_{500}$ averaged from the $25 \%$ heaviest precipitation AR/TS/ MCS days. The changes are spatially nonuniform including large areas of increases and decreases, indicating that changes in large-scale circulation may be important to regional changes in storm-associated $\omega_{500}$. The global area-weighted (frequencyweighted) mean changes in $\omega_{500}$ are respectively $-0.52 \%$ $(0.02 \%), 3.26 \%(0.38 \%)$, and $-0.75 \%(-0.03 \%) \mathrm{K}^{-1}$ for these AR, TS, and MCS days. Thus, on average, except for TS, the dynamic contribution to AR- and MCS-associated heavy precipitation appears to be small. The significant dynamical contribution to TS precipitation is consistent with the increase in TS intensity with warming (e.g., Liu et al. 2019). By contrast, the global mean value of $\delta \omega_{500} / \omega_{500}$ averaged over the $25 \%$ lightest precipitation AR/TS/MSC days exhibits a large reduction (not shown), indicating its significant role in suppressing AR/TS/ MCS-associated weaker precipitation.

Figures $12 \mathrm{~d}-\mathrm{f}$ show percentage changes in $q_{850}$ averaged over the $25 \%$ heaviest precipitation AR/TS/MCS days. The changes are spatially much more uniform than those in $\omega_{500}$ with a global mean increase of $\sim 7 \% \mathrm{~K}^{-1}$, roughly following the Clausius-Clapeyron (C-C) scaling of atmospheric water vapor content (e.g., Held and Soden 2006). Compared with Figs. 11a-c, the results suggest that changes in $q_{850}$ play a dominant role in precipitation change of the $25 \%$ heaviest precipitation AR/TS/MCS days, including both their global means and spatial distribution. Figure 13 further shows that the change in $q_{850}$ is primarily due to the changes in lowerlevel atmospheric temperature with the regions of larger increase in $q_{850}$ corresponding well with the regions of larger increase in $850-\mathrm{hPa}$ temperature. Thus, the thermodynamic component (i.e., $\delta q_{850}$ ) is the primary cause of the increase in AR/TS/MCS-associated precipitation intensity, with the dynamic and microphysical (residue; not shown) components playing only a secondary role.

\section{Summary}

ARs, TSs, and MCSs are fascinating weather phenomena that are often studied individually or through storm composites. Despite the notion that each of these phenomena may contribute significantly to global and regional hydrological 
(a) $\Delta$ frequency of AR days (mean:0.093\%/K)

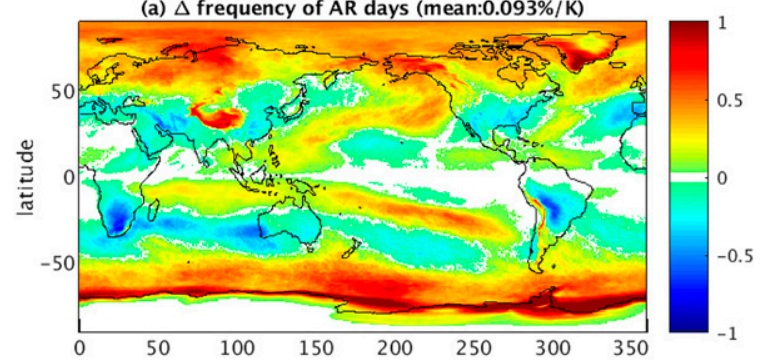

(b) $\Delta$ frequency of TS days (mean:- $0.027 \% / K$ )

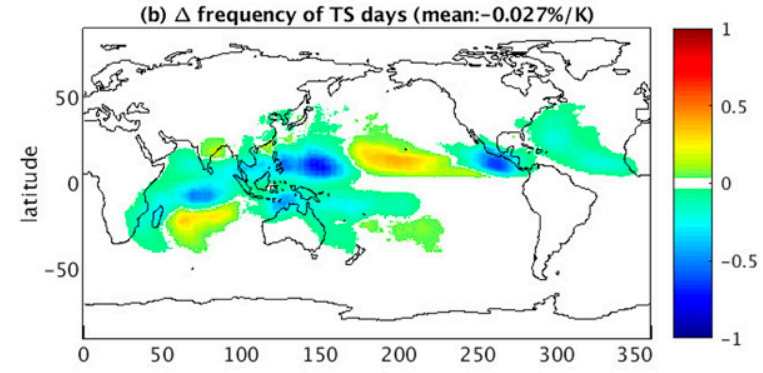

(c) $\Delta$ frequency of MCS days (mean:-0.099\%/K)

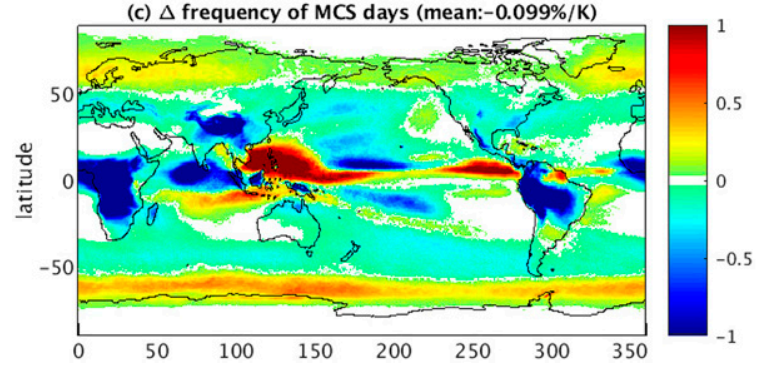

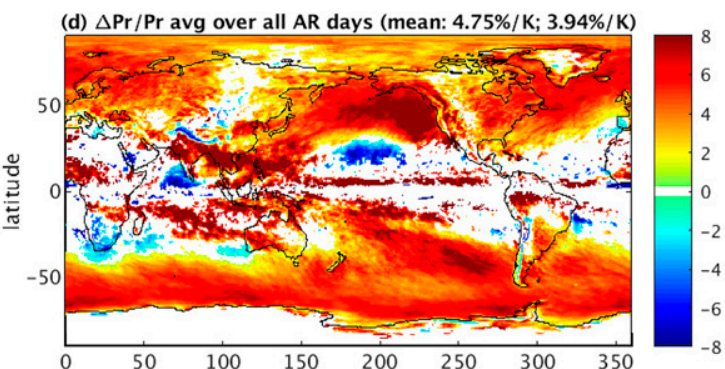
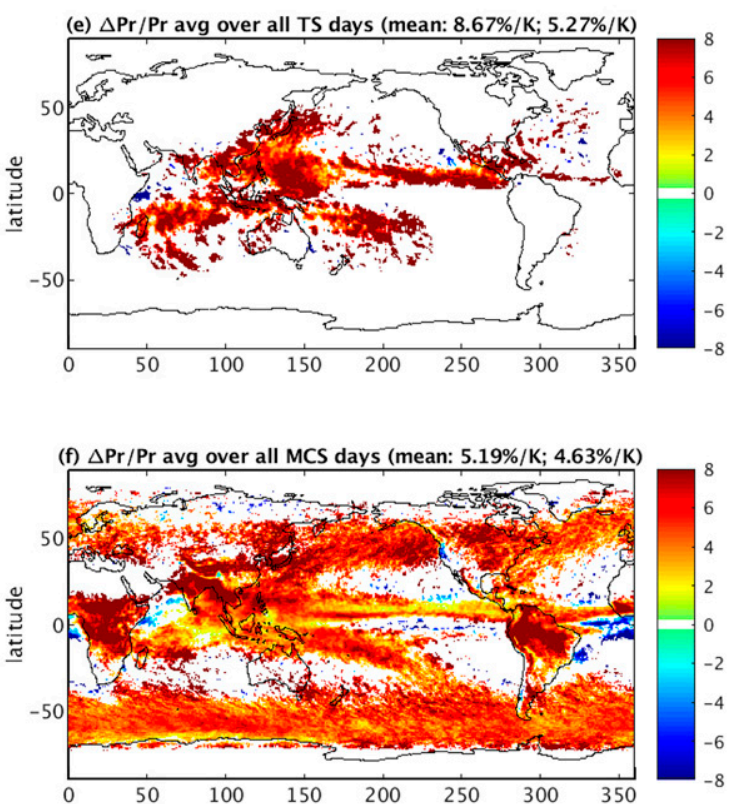

FIG. 10. Geographical distribution of changes in frequency of the (a) AR, (b) TS, and (c) MCS days (all normalized to per $1^{\circ}$ global mean surface warming; \% $\mathrm{K}^{-1}$ ) between P4K and CLIMO. The global area-weighted mean value is shown on the top of each panel. (d)-(f) As in (a)-(c), but for the percentage changes in daily precipitation rate (i.e., $\Delta P_{r} / P_{r}$, normalized to per $1^{\circ}$ global mean surface warming; \% $\mathrm{K}^{-1}$ ) averaged over all AR, TS, and MCS days, respectively. The grid cells with total number of AR/TS/MCS days less than 30 in CLIMO or P4K and the grid cells where $\Delta P_{r}$ is not statistically significant at $95 \%$ confidence level (based on $Z$ tests) are masked out. Two global measures of $\Delta P_{r} / P_{r}$ are shown on the top of each panel for (d)-(f). The first is the global area-weighted mean $\Delta P_{r} / P_{r}$ over all $\mathrm{AR} / \mathrm{TS} / \mathrm{MCS}$ regions. The second is the percentage change in AR/TS/MCS frequency weighted global mean precipitation from all AR/TS/ MCS days - that is, the percentage change in $\left[\overline{P_{r, \text { all } X}}\right]=\int_{y} \int_{x} \overline{P_{r, \text { all } X}}(x, y) F_{\text {all } X}(x, y) d x d y / \int_{y} \int_{x} F_{\text {all } X}(x, y) d x d y$, where $X=\mathrm{AR} / \mathrm{TS} / \mathrm{MCS}$ days, and $\overline{P_{r, \text { all } X}}$ and $F_{\text {all } X}$ denote respectively the mean precipitation and frequency averaged from all AR/TS/MCS days at each location $(x, y)$.

cycles, global-scale investigations of their collective effects have been lacking due to limited observational coverage, short data records, and model deficiencies in representing these events. GCM studies of these weather statistics focus mostly on the frequency of individual phenomena instead of their combined effect on global and regional hydrological cycles. Here we used the latest observational estimates of global high resolution daily precipitation for the period of 1979-2014 and the newly developed GFDL global high-resolution model (C192AM4) to provide for the first time a systematic quantification of the contributions of ARs, TSs, and MCSs to global and regional mean and extreme precipitation as well as their changes in a warmer climate. The results suggest that despite their occasional (13\%) occurrence globally, AR, TS, and MCS days together account for $\sim 55 \%$ of global mean precipitation and $\sim 75 \%$ of extreme precipitation, with daily rates exceeding its local 99th percentile. Regionally, these phenomena account for $80 \%-100 \%$ of extreme precipitation in essentially all parts of the world, where the local 99th percentile of daily precipitation is large and thus the disaster potential associated with the extreme precipitation is high. The model reproduces well the observed percentage of mean and extreme precipitation associated with AR, TS, and MCS days despite a significant overestimate of the 99th percentile of daily precipitation and the daily precipitation rate averaged over the top $25 \%$ of AR/TS/MCS days with the heaviest precipitation. 
(a) $\triangle \operatorname{Pr} / \operatorname{Pr}$ avg over $25 \%$ heaviest-Pr AR days ( $5.86 \% / K: 4.93 \% / K$ )

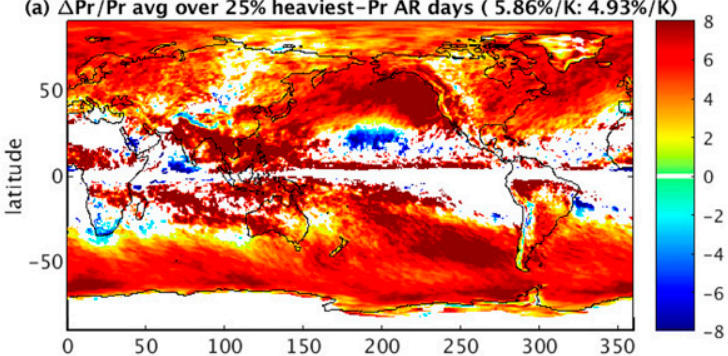

(b) $\Delta \operatorname{Pr} / \operatorname{Pr}$ avg over $25 \%$ heaviest-Pr TS days ( $8.78 \% / \mathrm{K} ; 5.96 \% / \mathrm{K}$ )

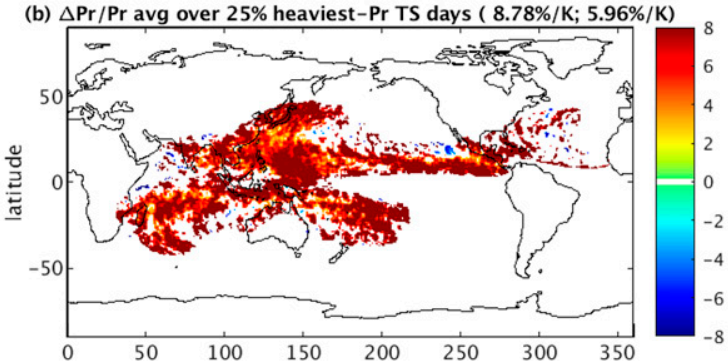

(c) $\Delta \operatorname{Pr} / \operatorname{Pr}$ avg over $25 \%$ heaviest-Pr MCS days ( $6.32 \% / K ; 6.08 \% / K)$

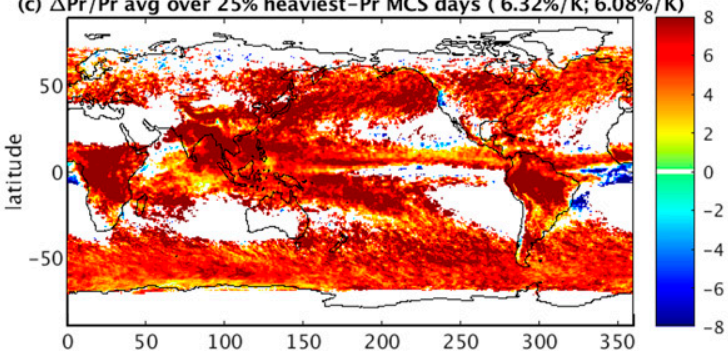

(d) $\Delta \mathrm{Pr} / \mathrm{Pr}$ avg over $25 \%$ lightest-Pr AR days $(0.37 \% / \mathrm{K} ; 0.83 \% / \mathrm{K})$

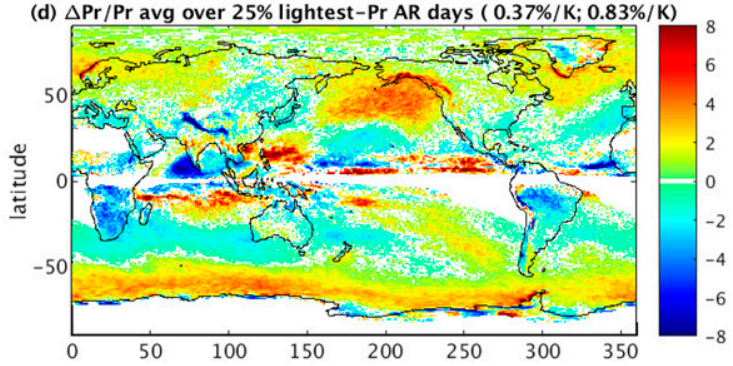

(e) $\Delta \mathrm{Pr} / \mathrm{Pr}$ avg over $25 \%$ lightest-Pr TS days $(2.40 \% / \mathrm{K} ; 1.97 \% / \mathrm{K})$

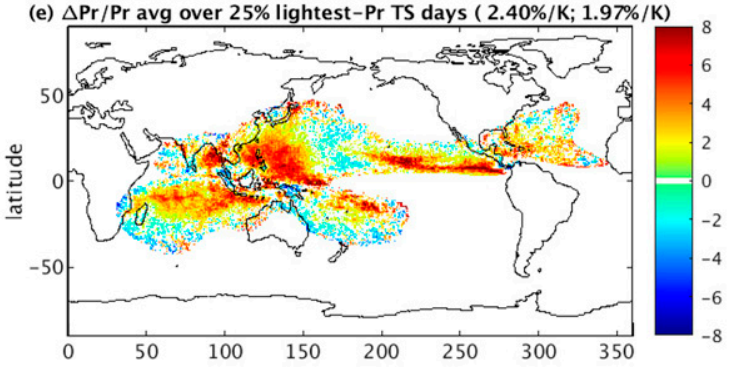

(f) $\triangle \mathrm{Pr} / \mathrm{Pr}$ avg over $25 \%$ lightest-Pr MCS days $(-0.61 \% / \mathrm{K} ;-0.73 \% / \mathrm{K})$

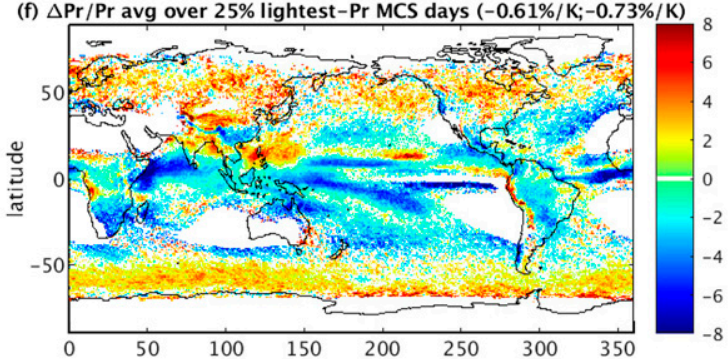

FIG. 11. (left) Percentage changes in daily precipitation rate (i.e., $\Delta P_{r} / P_{r}$, normalized to per $1^{\circ}$ global mean surface warming; \% $\mathrm{K}^{-1}$ ) averaged over the $25 \%$ heaviest precipitation (a) AR, (b) TS, and (c) MCS days. The grid cells with total number of the $25 \%$ heaviest precipitation AR/TS/MCS days less than 30 in CLIMO or P4K and the grid cells where $\Delta P_{r}$ is not statistically significant at $95 \%$ confidence level (based on $Z$ tests) are masked out. Two global measures of $\Delta P_{r} / P_{r}$ are shown on the top of each panel in (a)-(c). The first is the global area-weighted mean $\Delta P_{r} / P_{r}$ over the regions of $25 \%$ heaviest precipitation AR/TS/MCS days. The second is the percentage change in global AR/TS/MCS frequency weighted mean $P_{r}$ from the $25 \%$ heaviest precipitation AR/TS/MCS days - that is, the percentage change in $\left[\overline{P_{r, h 25 X}}\right]=\int_{y} \int_{x} \overline{P_{r, h 25 X}}(x, y) F_{h 25 X}(x, y) d x d y / \int_{y} \int_{x} F_{h 25 X}(x, y) d x d y$, where $X=$ AR/TS/MCS days, and $\overline{P_{r, h 25 X}}$ and $F_{h 25 X}$ denote respectively the mean precipitation and frequency averaged from the $25 \%$ heaviest precipitation AR/TS/MCS days at each location ( $x, y$ ). (right) As at left, but for $\Delta P_{r} / P_{r}$ averaged over the $25 \%$ lightest precipitation (d) AR, (e) TS, and (f) MCS days.

Under an idealized global warming scenario (i.e., uniform SST warming), the model-simulated changes in geographical distribution of annual mean precipitation correspond well with the total changes in precipitation associated with AR, TS, and MCS days, with the net changes being dominated by the AR days in the middle and high latitudes and by MCS and TS days in the tropics and subtropics. Globally, the modeled frequency of AR days increases slightly and migrates toward higher latitudes while the frequency of TS days tends to increase over the central North Pacific and part of the south Indian Ocean with a decrease elsewhere. The frequency of MCS days tends to increase over parts of the equatorial western and eastern Pacific warm pools and high latitudes and decreases over most tropical and subtropical regions with the largest reduction over the tropical land-covered regions. The daily precipitation rate averaged over AR, TS, and MCS days increases by roughly $5 \% \mathrm{~K}^{-1}$, slightly less than the C-C scaling of atmospheric water vapor content. This increase is due primarily to a larger increase (closer to C-C scaling) in precipitation from the $25 \%$ heaviest precipitation days, with the weaker precipitation days exhibiting a much smaller increase or even a decrease.

This changing character of storm-associated precipitation has important implications for local hydrology and water resource management because steady moderate rainfall would soak into the soil and benefit plants, while heavy rainfall may 

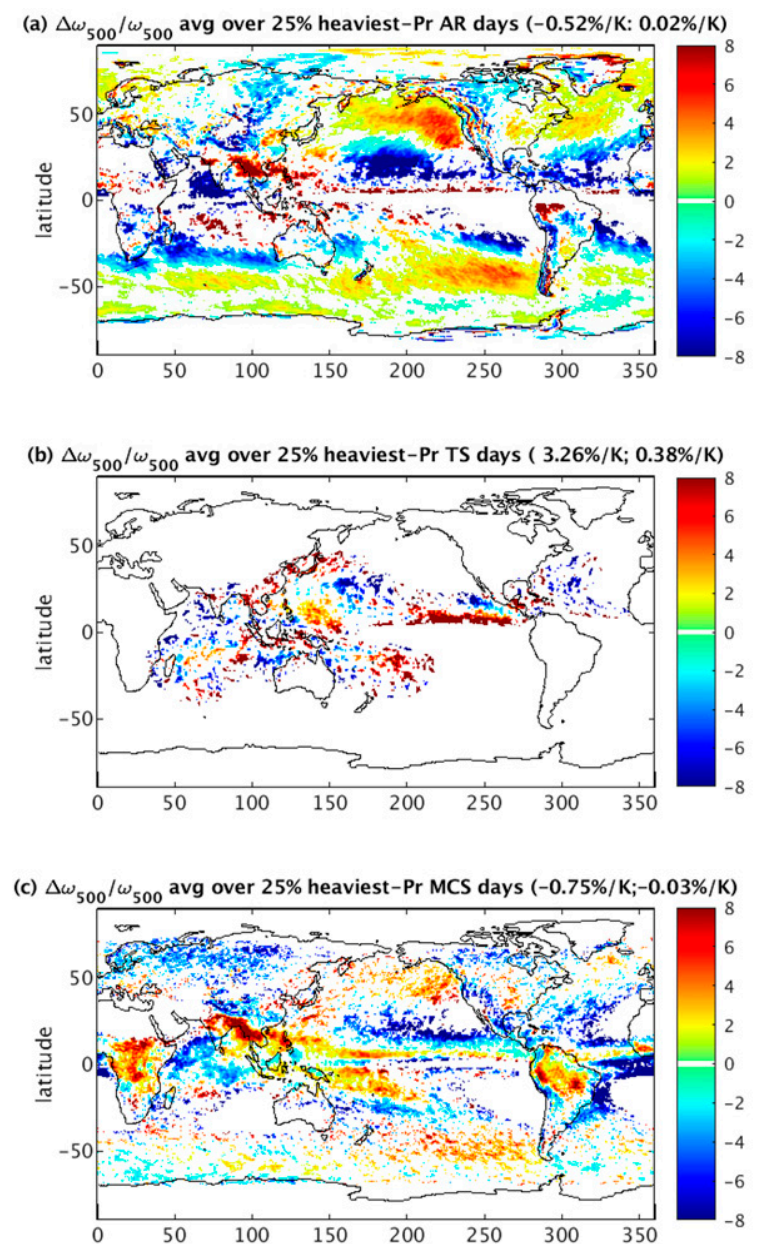

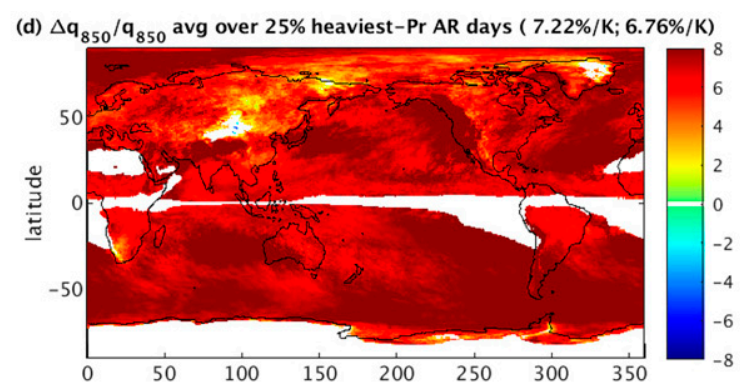

(e) $\Delta q_{850} / q_{850}$ avg over $25 \%$ heaviest-Pr TS days ( $\left.6.98 \% / K ; 6.90 \% / K\right)$
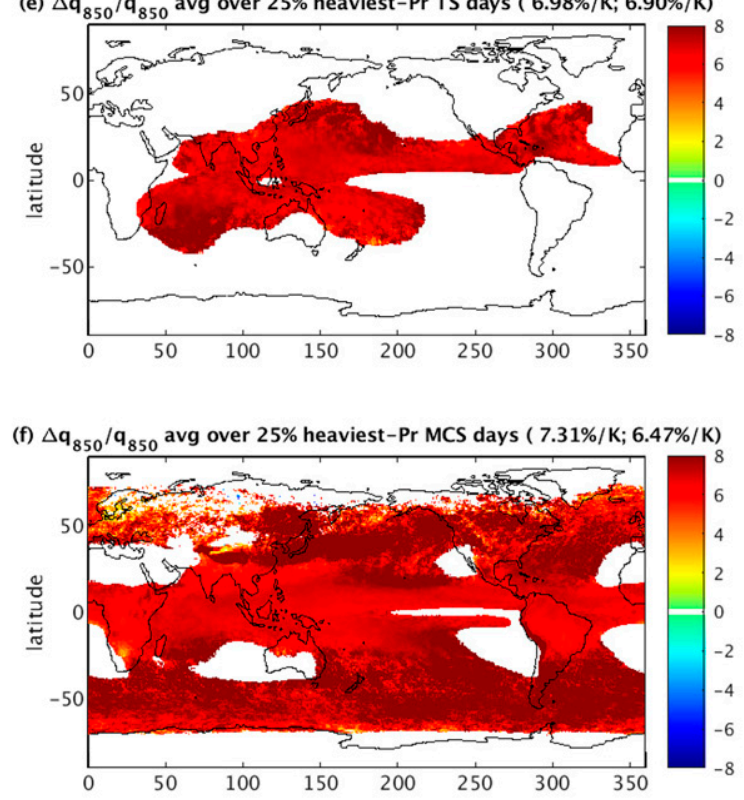

FIG. 12. (left) Percentage changes in daily $500-\mathrm{hPa}$ pressure velocity (i.e., $\Delta \omega_{500} / \omega_{500}$, normalized to per $1^{\circ}$ global mean surface warming; $\% \mathrm{~K}^{-1}$ ) averaged over the $25 \%$ heaviest precipitation (a) AR, (b) TS, and (c) MCS days. The grid cells with total number of the $25 \%$ heaviest precipitation AR/TS/MCS days less than 30 in CLIMO or P4K and the grid cells where $\Delta \omega_{500}$ is not statistically significant at $95 \%$ confidence level (based on $Z$ tests) are masked out. Two global measures of $\Delta \omega_{500} / \omega_{500}$ are shown on the top of each panel in (a)-(c). The first is the global area-weighted mean $\Delta \omega_{500} / \omega_{500}$ over the regions of $25 \%$ heaviest precipitation AR/TS/MCS days. The second is the percentage change in global AR/TC/MCS frequency weighted mean $\omega_{500}$ averaged from the $25 \%$ heaviest precipitation AR/TS/MCS daysthat is, the percentage change in $\left[\overline{\omega_{500, h 25 X}}\right]=\int_{y} \int_{x} \overline{\omega_{500, h 25 X}}(x, y) F_{h 25 X}(x, y) d x d y / \int_{y} \int_{x} F_{h 25 X}(x, y) d x d y$, where $X=\mathrm{AR} / \mathrm{TS} / \mathrm{MCS}$ days and $\overline{\omega_{500, h 25 X}}$ and $F_{h 25 X}$ denote respectively the mean $\omega_{500}$ and frequency averaged from the $25 \%$ heaviest precipitation AR/TS/MCS days at each location $(x, y)$. (right) As at left, but for the percentage changes in 850 -hPa specific humidity $q_{850}$ averaged over the $25 \%$ heaviest precipitation (d) AR, (e) TS, and (f) MCS days.

cause local flash floods and runoff, making soil much drier in the long term. This change of precipitation characteristics is also important to the global hydrological cycle and regional extreme precipitation since it is the $25 \%$ heaviest precipitation $\mathrm{AR} / \mathrm{TS} / \mathrm{MCS}$ days that dominate the increases in global mean precipitation and the frequency of catastrophic floods in a warmer climate. Our results suggest that the precipitation response of the $25 \%$ heaviest precipitation $\mathrm{AR} / \mathrm{TS} / \mathrm{MCS}$ days is dominated by the thermodynamic component, with dynamic and microphysical components playing a secondary role.

Finally, it is worth noting a few caveats of the present study. First, the use of uniform SST warming will not be able to represent the effects of SST warming patterns, which can strongly affect regional changes in AR/TS/MCS frequency in a warmer climate (e.g., Villarini and Vecchi 2012; Zhao et al. 2009; Zhao and Held 2012; Zhao 2020). For example, using CMIP5 models and a statistical downscaling approach, Villarini and Vecchi (2012) demonstrated that the twenty-first-century projections of North Atlantic (NA) TSs will depend on the relative SST warming over the tropical Atlantic. They further identified the dominant sources of uncertainty in determining this relative SST warming and how they may evolve during different periods of the twenty-first century. They pointed out large uncertainties in both internal climate variability and modeled 

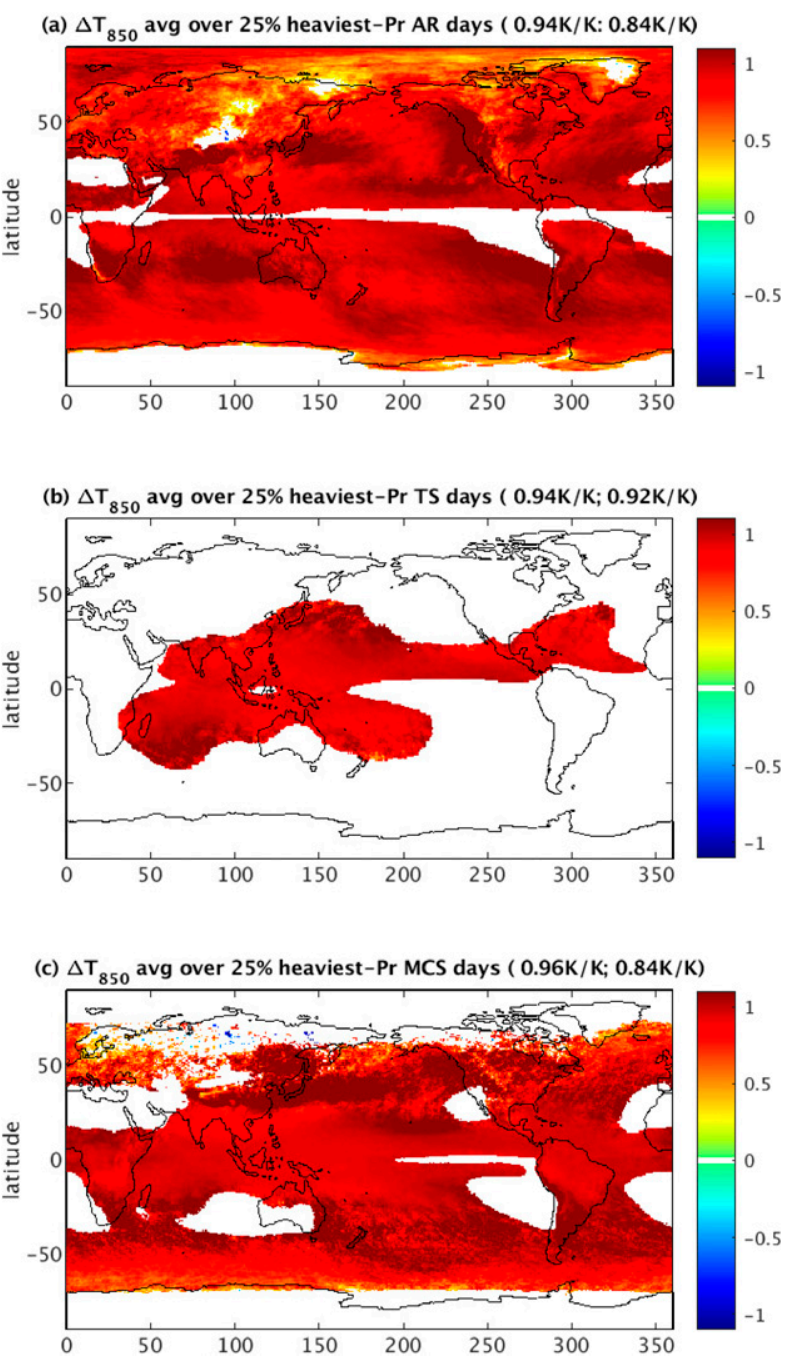

FIG. 13. As Figs. 12d-f, but for the absolute changes in temperature at $850 \mathrm{hPa}$ (i.e., $\Delta T_{850}$, normalized to per $1^{\circ}$ global mean surface warming; $\mathrm{K} \mathrm{K}^{-1}$ ) averaged over the $25 \%$ heaviest precipitation (a) AR, (b) TS, and (c) MCS days.

response in SST warming patterns to radiative forcings throughout the twenty-first century. Given the complexity of future projections of regional change in AR/TS/MCS frequency, one should think of the present study as only one component (i.e., global mean SST warming) of the future projection, which must be superimposed with other equally important components (i.e., SST warming patterns and changes in forcing agents). Second, there are significant uncertainties in detecting these storm systems (e.g., thresholds used by the detection methods) and computing their associated precipitation (e.g., impacting area and duration); this may be especially true for MCSs. In addition, the model also has significant biases in simulating the regional distribution of storm frequencies. For example, the model tends to overproduce MCS frequencies over the western Pacific and underestimate them over the equatorial south Indian Ocean. Although our sensitivity tests indicate this is likely due to the model's error instead of the MCS detection method, both the uncertainties in MCS detection and the model's ability in reproducing the observed regional distribution of MCS frequency may affect the model's future MCS projections, especially at regional scales. It could also affect the partition of dynamical and thermodynamic contributions to local changes in MCS-associated precipitation. Thus, our results would need to be further validated and compared with other studies using different models and different MCS detection methods in the future.

Acknowledgments. I am grateful for helpful comments and suggestions from Tom Knutson, Steve Garner, Leo Donner, Michael A. Zhao, and three anonymous reviewers whose comments and suggestions have helped to improve the paper.

Data availability statement. The C192AM4 model simulation data can be obtained from https://esgf-node.llnl.gov/search/ cmip6/. The Multi-Source Weighted-Ensemble Precipitation (MSWEP-v2) dataset are available at http://www.gloh2o.org/ mswep/. The ERA-Interim data are available at https://apps. ecmwf.int/datasets/data/interim-full-daily/levtype=sfc/. The Cloud Archive User Service (CLAUS) multisatellite infrared brightness temperature dataset is available at https://data.ceda.ac.uk/ badc/claus/data. The International Best Track Archive for Climate Stewardship (IBTrACS) data are available at https:/ www.ncdc.noaa.gov/ibtracs/index.php? name=ib-v4-access. The AM4 model code is provided at http://data1.gfdl. noaa.gov/nomads/forms/am4.0/.

\section{REFERENCES}

Beck, H. E., E. F. Wood, M. Pan, C. K. Fisher, D. M. Miralles, A. I. J. M. van Dijk, T. R. McVicar, and R. F. Adler, 2019: MSWEP V2 global 3-hourly $0.1^{\circ}$ precipitation: Methodology and quantitative assessment. Bull. Amer. Meteor. Soc., 100, 473-500, https://doi.org/10.1175/BAMS-D-17-0138.1.

Bony, S., G. Bellon, D. Klocke, S. Sherwood, S. Fermepin, and S. Denvil, 2013: Robust direct effect of carbon dioxide on tropical circulation and regional precipitation. Nat. Geosci., 6, 447-451, https://doi.org/10.1038/ngeo1799.

Cheeks, H. M., S. Fueglistaler, and S. T. Garner, 2020: A satellitebased climatology of central and southeastern U.S. mesoscale convective systems. Mon. Wea. Rev., 148, 2607-2621, https:// doi.org/10.1175/MWR-D-20-0027.1.

Delworth, T. L., and Coauthors, 2020: SPEAR: The next generation GFDL modeling system for seasonal to multidecadal prediction and projection. J. Adv. Model. Earth Syst., 12, e2019MS001895, https://doi.org/10.1029/2019MS001895.

Dettinger, M. D., 2013: Atmospheric rivers as drought busters on the U.S. West Coast. J. Hydrometeor., 14, 1721-1732, https:// doi.org/10.1175/JHM-D-13-02.1.

Dong, W., M. Zhao, Y. Ming, and V. Ramaswamy, 2021: Representation of tropical mesoscale convective systems in a general circulation model: Climatology and response to global warming. J. Climate, 34, 5657-5671, https://doi.org/10.1175/ JCLI-D-20-0535.1.

Dunne, J. P., and Coauthors, 2020: The GFDL Earth System Model version 4.1 (GFDL-ESM4.1): Model description and 
simulation characteristics. J. Adv. Model. Earth Syst., 12, e2019MS002015, https://doi.org/10.1029/2019MS002015.

Ellingson, R. G., and R. R. Ferraro, 1983: An examination of a technique for estimating the longwave radiation budget from satellite radiance observations. J. Climate Appl. Meteor., 22, 1416-1423, https://doi.org/10.1175/1520-0450(1983)022<1416: AEOATF $>2.0 . \mathrm{CO} ; 2$.

Emanuel, K., 2018: 100 years of progress in tropical cyclone. A Century of Progress in Atmospheric and Related Sciences, Meteor. Monogr., No. 59, Amer. Meteor. Soc., 15.1-15.68, https://doi.org/10.1175/AMSMONOGRAPHS-D-18-0016.1.

Espinoza, V., D. E. Waliser, B. Guan, D. A. Lavers, and F. M. Ralph, 2018: Global analysis of climate change projection effects on atmospheric rivers. Geophys. Res. Lett., 45, 42994308, https://doi.org/10.1029/2017GL076968.

Eyring, V., S. Bony, G. Meehl, C. A. Senior, B. Stevens, R. Stouffer, and K. E. Taylor, 2016: Overview of the Coupled Model Intercomparison Project Phase 6 (CMIP6) experimental design and organization. Geosci. Model Dev., 9, 19371958, https://doi.org/10.5194/gmd-9-1937-2016.

Feng, Z., L. R. Leung, S. Hagos, R. A. Houze, C. D. Burleyson, and K. Balaguru, 2016: More frequent intense and long-lived storms dominate the springtime trend in central US rainfall. Nat. Commun., 7, 13429, https://doi.org/10.1038/ncomms13429.

—, and Coauthors, 2021: A global high-resolution mesoscale convective system database using satellite-derived cloud tops, surface precipitation, and tracking. J. Geophys. Res. Atmos., 126, e2020JD034202, https://doi.org/10.1029/2020JD034202.

Gao, Y., and L. R. Leung, 2016: Uncertainties in projecting future changes in atmospheric rivers and their impacts on heavy precipitation over Europe. J. Climate, 29, 6711-6726, https:// doi.org/10.1175/JCLI-D-16-0088.1.

Guan, B., and D. E. Waliser, 2015: Detection of atmospheric rivers: Evaluation and application of an algorithm for global studies. J. Adv. Model. Earth Syst., 120, 12514-12535, https://doi.org/10. 1002/2015JD024257.

Haarsma, R. J., and Coauthors, 2016: High Resolution Model Intercomparison Project (HighResMIP v1.0) for CMIP6. Geosci. Model Dev., 9, 4185-4208, https://doi.org/10.5194/ gmd-9-4185-2016.

Hagos, S., L. R. Leung, J.-H. Yoon, J. Lu, and Y. Gao, 2016: A projection of changes in landfalling atmospheric river frequency and extreme precipitation over western North America from the large ensemble CESM simulations. Geophys. Res. Lett., 43, 1357-1363, https://doi.org/10.1002/2015GL067392.

Held, I. M., and B. J. Soden, 2006: Robust responses of the hydrological cycle to global warming. J. Climate, 19, 5686-5699, https://doi.org/10.1175/JCLI3990.1.

—, and M. Zhao, 2011: The response of tropical cyclone statistics to an increase in $\mathrm{CO}_{2}$ with fixed sea surface temperatures. J. Climate, 24, 5353-5364, https://doi.org/10.1175/JCLID-11-00050.1.

— , and Coauthors, 2019: Structure and performance of GFDL's CM4.0 climate model. J. Adv. Model. Earth Syst., 11, 36913727, https://doi.org/10.1029/2019MS001829.

Hodges, K. I., D. W. Chappell, G. J. Robinson, and G. Yang, 2000: An improved algorithm for generating global window brightness temperatures from multiple satellite infrared imagery. J. Atmos. Oceanic Technol., 17, 1296-1312, https://doi. org/10.1175/1520-0426(2000)017<1296:AIAFGG > 2.0.CO;2.

Horn, M., and Coauthors, 2014: Tracking scheme dependence of simulated tropical cyclone response to idealized climate simulations. J. Climate, 27, 9197-9213, https://doi.org/10.1175/ JCLI-D-14-00200.1.

Houze, R. A., 2004: Mesoscale convective systems. Rev. Geophys., 42, 1-43, https://doi.org/10.1029/2004RG000150.

— 2018: 100 years of research on mesoscale convective systems. A Century of Progress in Atmospheric and Related Sciences, Meteor. Monogr., No. 59, Amer. Meteor. Soc., 17.1-17.54, https://doi.org/10.1175/AMSMONOGRAPHS-D18-0001.1.

Huang, X. M., C. Q. Hu, X. Huang, Y. Chu, Y. H. Tseng, G. J. Zhang, and Y. L. Lin, 2018: A long-term tropical mesoscale convective systems dataset based on a novel objective automatic tracking algorithm. Climate Dyn., 51, 3145-3159, https://doi.org/10.1007/s00382-018-4071-0.

Jiang, H., and E. Zipser, 2010: Contribution of tropical cyclones to the global precipitation from eight seasons of TRMM data: Regional, seasonal, and interannual variations. J. Climate, 23, 1526-1543, https://doi.org/10.1175/2009JCLI3303.1.

Knapp, K. R., M. C. Kruk, D. H. Levinson, H. J. Diamond, and C. J. Neumann, 2010: The International Best Track Archive for Climate Stewardship (IBTrACS). Bull. Amer. Meteor. Soc., 91, 363-376, https://doi.org/10.1175/2009BAMS2755.1.

Knutson, T., and Coauthors, 2010: Tropical cyclones and climate change. Nat. Geosci., 3, 157-163, https://doi.org/10.1038/ ngeo779.

— , and Coauthors, 2019: Tropical cyclones and climate change assessment: Part I. Detection and attribution. Bull. Amer. Meteor. Soc., 100, 1987-2007, https://doi.org/10.1175/BAMSD-18-0189.1.

— - and Coauthors, 2020: Tropical cyclones and climate change assessment: Part II. Projected response to anthropogenic warming. Bull. Amer. Meteor. Soc., 101, E303-E322, https:// doi.org/10.1175/BAMS-D-18-0194.1.

Lavers, D. A., and G. Villarini, 2013: The nexus between atmospheric rivers and extreme precipitation across Europe. Geophys. Res. Lett., 40, 3259-3264, https://doi.org/10.1002/grl.50636.

— , and — 2015: The contribution of atmospheric rivers to precipitation in Europe and the United States. J. Hydrol., 522, 382-390, https://doi.org/10.1016/j.jhydrol.2014.12.010.

Liu, M., G. A. Vecchi, J. A. Smith, and T. R. Knutson, 2019: Causes of large projected increases in hurricane precipitation rates with global warming. npj Climate Atmos. Sci., 2, 38, https://doi.org/10.1038/s41612-019-0095-3.

Muller, C. J., and Y. Takayabu, 2020: Response of precipitation extremes to warming: What have we learned from theory and idealized cloud-resolving simulations, and what remains to be learned? Environ. Res. Lett., 15, 035001, https://oi.org/ 10.1088/1748-9326/ab7130.

Murakami, H., T. L. Delworth, W. F. Cooke, M. Zhao, B. Xiang, and P. Hsu, 2020: Detected climatic change in global distribution of tropical cyclones. Proc. Natl. Acad. Sci. USA, 117, 10706-10714, https://doi.org/10.1073/pnas.1922500117.

Nayak, M. A., and G. Villarini, 2017: A long-term perspective of the hydroclimatological impacts of atmospheric rivers over the central United States. Water Resour. Res., 53, 1144-1166, https://doi.org/10.1002/2016WR019033.

Ohring, G., A. Gruber, and R. Ellingson, 1984: Satellite determinations of the relationship between total longwave radiation flux and infrared window radiance. J. Climate Appl. Meteor., 23, 416-425, https://doi.org/10.1175/1520-0450(1984)023<0416: SDOTRB $>2.0 . \mathrm{CO} ; 2$.

Prat, O. P., and B. R. Nelson, 2013: Precipitation contribution of tropical cyclones in the southeastern United States from 1998 
to 2009 using TRMM satellite data. J. Climate, 26, 1047-1062, https://doi.org/10.1175/JCLI-D-11-00736.1.

— , and - 2016: On the link between tropical cyclones and daily rainfall extremes derived from global satellite observations. J. Climate, 29, 6127-6135, https://doi.org/10.1175/JCLID-16-0289.1.

Ralph, F. M., P. J. Neiman, G. A. Wick, S. I. Gutman, M. D. Dettinger, D. R. Cayan, and A. B. White, 2006: Flooding on California's Russian River: Role of atmospheric rivers. Geophys. Res. Lett., 33, L13801, https://doi.org/10.1029/2006GL026689.

_ J. J. Rutz, J. M. Cordeira, M. Dettinger, M. Anderson, D. Reynolds, L. J. Schick, and C. Smallcomb, 2019: A scale to characterize the strength and impacts of atmospheric rivers. Bull. Amer. Meteor. Soc., 100, 269-289, https://doi.org/10. 1175/BAMS-D-18-0023.1.

Scoccimarro, E., S. Gualdi, G. Villarini, G. A. Vecchi, and M. Zhao, 2014: Intense precipitation events associated with landfalling tropical cyclones in response to a warmer climate and increased $\mathrm{CO}_{2}$. J. Climate, 27, 4642-4654, https://doi.org/10. 1175/JCLI-D-14-00065.1.

Shaevitz, D., and Coauthors, 2014: Characteristics of tropical cyclones in high-resolution models in the present climate. $J$. Adv. Model. Earth Syst., 6, 1154-1172, https://doi.org/10.1002/ 2014MS000372.

Shields, C. A., and J. T. Kiehl, 2016: Atmospheric river landfalllatitude changes in future climate simulations. Geophys. Res. Lett., 43, 8775-8782, https://doi.org/10.1002/2016GL070470.

_ , and Coauthors, 2018: Atmospheric River Tracking Method Intercomparison Project (ARTMIP): Project goals and experimental design. Geosci. Model Dev., 11, 2455-2474, https:// doi.org/10.5194/gmd-11-2455-2018.

Slinskey, E. A., P. C. Loikith, D. E. Waliser, B. Guan, and A. Martin, 2020: A climatology of atmospheric rivers and associated precipitation for the seven U.S. National Climate Assessment regions. J. Hydrometeor., 21, 2439-2456, https:// doi.org/10.1175/JHM-D-20-0039.1.
Villarini, G., and G. A. Vecchi, 2012: Twenty-first-century projections of North Atlantic tropical storms from CMIP5 models. Nat. Climate Change, 2, 604-607, https://doi.org/10.1038/ nclimate1530

Zhao, M., and Coauthors, 2018a: The GFDL global atmosphere and land model AM4.0/LM4.0: 1. Simulation characteristics with prescribed SSTs. J. Adv. Model. Earth Syst., 10, 691-734, https://doi.org/10.1002/2017MS001208.

_ , and Coauthors, 2018b: The GFDL global atmosphere and land model AM4.0/LM4.0: 2. Model description, sensitivity studies, and tuning strategies. J. Adv. Model. Earth Syst., 10, 735-769, https://doi.org/10.1002/2017MS001209.

— 2020: Simulations of atmospheric rivers, their variability, and response to global warming using GFDL's new high-resolution general circulation model. J. Climate, 33, 1028710303, https://doi.org/10.1175/JCLI-D-20-0241.1.

— , and I. M. Held, 2012: TC-permitting GCM simulations of hurricane frequency response to sea surface temperature anomalies projected for the late 21 st century. J. Climate, 25, 2995-3009, https://doi.org/10.1175/JCLI-D-11-00313.1.

,-- , S.-J. Lin, and G. A. Vecchi, 2009: Simulations of global hurricane climatology, interannual variability, and response to global warming using a 50-km resolution GCM. J. Climate, 22, 6653-6678, https://doi.org/10.1175/2009JCLI3049.1.

- - — and G. A. Vecchi, 2010: Retrospective forecasts of the hurricane season using a global atmospheric model assuming persistence of SST anomalies. Mon. Wea. Rev., 138, 38583868, https://doi.org/10.1175/2010MWR3366.1.

$\longrightarrow,-$, and S.-J. Lin, 2012: Some counterintuitive dependencies of tropical cyclone frequency on parameters in a GCM. J. Atmos. Sci., 69, 2272-2283, https://doi.org/10.1175/JAS-D11-0238.1.

Zhu, Y., and R. E. Newell, 1994: Atmospheric rivers and bombs. Geophys. Res. Lett., 21, 1999-2002, https://doi.org/10.1029/ 94GL01710. 